\title{
Bioleaching of Copper from Electronic Waste Using
}

\section{Aspergillus niger}

\author{
Hayat M. Sharada ${ }^{1}$, Sawsan A. Abdel-Halim ${ }^{1}$, Mohamed A. Hafez ${ }^{2}$ (D), Tarek A. Elbarbary ${ }^{3}$, Yasmeen \\ Abdel-Fatah ${ }^{3, *}$, Ibrahim A. Ibrahim ${ }^{3}$ \\ 1 Biochemistry Department, Faculty of Science, Helwan University, Egypt \\ 2 Botany and Microbiology Department, Faculty of Science, Al-Azhar University, Egypt \\ 3 Mineral Processing Department, Central Metallurgical R \& D Institute (CMRDI), Cairo, Egypt \\ * Correspondence: yasmeen.madeeh@yahoo.com (Y.A.-F.);
}

Scopus Author ID 57345468800

Received: 26.09.2021; Revised: 10.11.2021; Accepted: 14.10.2021; Published: 11.12.2021

\begin{abstract}
The recycling of printed circuit boards (PCBs) causes environmental problems by releasing dioxins and furans. The objective of this study is the recovery of copper from PCBs through the bioleaching process using Aspergillus niger which was isolated from the surface of Abu Tartur phosphate. In the bioleaching process, the optimum conditions were used to modify ammonium medium with inoculum spore size are $2 \times 10^{6} \mathrm{SFU} / 50 \mathrm{ml}$ for 5 days at $30^{\circ} \mathrm{C}$ in a pulp of $0.5 \%$ solid 150 mesh particle size and aeration at $200 \mathrm{rpm}$. Different carbon and nitrogen sources were used. Glucose $(1.5 \%)$ and ammonium chloride $(0.2 \%)$ were the best source of carbon and nitrogen, respectively. Also, the optimum initial medium's $\mathrm{pH}$ was 7 . At these conditions, about $100 \%$ of $\mathrm{Cu}$ was extracted. The mechanism of bioleaching was studied by detecting the production of organic acid through using brome cresol green as an indicator and HPLC analysis. The color change of agar medium of the incubated plate with A. niger from blue to yellow, and HPLC analysis showed detection malic and citric acids in the sample in presence e-waste higher than the sample without e-waste. E-waste before and after the bioleaching process was investigated using SEM. The surface of e-waste becomes more smooth and porous due to the bioleaching process.
\end{abstract}

Keywords: bioleaching; Aspergillus niger; copper; printed circuit boards waste.

(C) 2021 by the authors. This article is an open-access article distributed under the terms and conditions of the Creative Commons Attribution (CC BY) license (https://creativecommons.org/licenses/by/4.0/)

\section{Introduction}

Electric and electronic wastes (e-wastes) have been defined [1] as any waste dependent on electric currents or electromagnetic fields to work properly. Global waste electrical and electronic equipment (WEEE) generation was 41.8 million tons (Mt) in 2014 and is likely to increase to $50 \mathrm{Mt}$ in 2018 [2]. The problem with e-waste is its growing volume, toxicity, and content of valuable resources (e.g., gold), which are lost when e-waste is disposed of [3]. Ewaste contains approximately $40 \%$ of metals, including base metals, precious metals, and rare earth elements $[4,5]$.

The copper content in the printed circuit board (PCB) is 10-30 mass \%, the highest among the metallic elements [6]. Copper is an industrially significant metal, widely used in building construction (wiring, plumbing, and weather proofing), electrical and electronic products, transportation equipment, and industrial machinery [7]. Thus, the recovery of copper from e-waste is important to conserve the environment and metal resources. Their recovery is 
typically achieved by pyro-metallurgical and hydrometallurgical processes, with a certain energy and environmental disadvantages $[8,9]$.

The bioleaching process is now emerging as exploitable commercial technology applicable for metal extraction from electronic waste and low-grade ores. Using bioleaching techniques, the efficiency of recovery of metals can be increased, as revealed in copper and gold mining, where low-grade ores are biologically treated to obtain metal values, which are not accessible by conventional treatments (mechanical and thermal) [10].

Various lithotrophic and organotrophic microorganisms mediate the leaching processes [11]. Mainly, three groups of microorganisms are classified in bioleaching, namely (a) chemolithotrophic prokaryotes, including bacteria and archaea, (b) heterotrophic bacteria, and (c) heterotrophic fungi [12].

Heterotrophic bacteria and fungi are involved in bioleaching with microbial production of organic acids [13]. Organic acids play a role as bioleaching agents [14]. Also, other metabolites could play a role as leaching agents for extracting metals from waste material. In most cases of heterotrophic bioleaching, organic acids directly solubilize metals [15].

In this work, different factors affecting the bioleaching of copper from PCBs were studied by using Aspergillus niger to reach the maximum dissolution of copper.

\section{Materials and Methods}

\subsection{Materials.}

\subsubsection{Chemical composition of PCBs waste.}

The scraps of PCBs were first to cut into small pieces manually, then crushed by the high-speed universal pulverizer for $2 \mathrm{~min}$, and finally sieved. Chemical analysis of this PCBs sample was determined by XRF analysis, and crystalline phases were determined by XRD analysis.

\subsubsection{Microorganism.}

Aspergillus niger was isolated from Abu Tarture phosphate ore as described by Elbarbary et al. [16].

\subsubsection{Culture media.}

They were used Sabouraud-dextrose medium [17], contains (g/l):P peptone10, Dextrose 40.0, Agar 15.0 Final pH 5.6 \pm 0.2 at $25^{\circ} \mathrm{C}$. Modified malt-yeast extract medium [18], contains (g\l): Glucose, $10 \mathrm{~g}$; Peptone, $5.0 \mathrm{~g}$; Yeast extract, 3.0g; Agar, $20.0 \mathrm{~g}$, Distilled water, 1.0 Liter and adjust $\mathrm{pH}$ to 6.8 before autoclaving, autoclave at $121^{\circ} \mathrm{C}$ for $15 \mathrm{~min}$. this medium is solidified by $15 \mathrm{~g}$ agar per liter. Modified Czapek's Dox medium [19], contains $(\mathrm{g} / \mathrm{L})$ : $\mathrm{NaNO}_{3}, 2 ; \mathrm{Ca}_{3}\left(\mathrm{PO}_{4}\right)_{2}, 1 ; \mathrm{MgSO}_{4} .7 \mathrm{H}_{2} \mathrm{O}, 0.5 ; \mathrm{KCl}, 0.5 ; \mathrm{FeSO}_{4} .5 \mathrm{H}_{2} \mathrm{O}$ traces; sucrose, 30 and 1 liter distilled water. Modified ammonium medium [20], contains ( $\mathrm{g} \backslash \mathrm{L}$ ): Sucrose, 20; $\mathrm{Ca}_{3}$ $\left(\mathrm{PO}_{4}\right)_{2}, 5 ; \mathrm{MgSO}_{4} .7 \mathrm{H}_{2} \mathrm{O}, 1 ; \mathrm{NH}_{4} \mathrm{Cl}, 2$ and 1 liter distilled water. 


\subsection{Methods.}

2.2.1. Tolerance of Aspergillus niger to various concentrations of copper.

Modified malt extract agar medium with various concentrations of $\mathrm{CuSO}_{4}$ ranging from $(100-1000 \mathrm{ppm})$ was prepared, then put one disc of fungus in each plate and incubated at $30^{\circ}$ C. The diameter of Aspergillus niger growth was measured daily to know the activity of fungus in the presence of various concentrations of copper [21].

\subsubsection{Types of bioleaching methods.}

Three types of bioleaching methods, one-step, two-step, and spent medium method, were tested in the bioleaching process as the following:

One-step bioleaching method, $50 \mathrm{~mL}$ of modified malt extract medium was prepared with inoculation $2 \times 10^{6} \mathrm{SFU}$ and addition $0.25 \mathrm{~g}$ of PCBs at the same time. The incubated temperature was $30 \mathrm{C}^{\circ}$ and shaking speed $180 \mathrm{rpm}$. The concentration of copper was measured daily.

In the two-step, bioleaching method, culturing of $2 \times 10^{6} \mathrm{SFU} / 50 \mathrm{~mL}$ was prepared firstly for three days, then added $0.25 \mathrm{~g}$ PCBs and incubated at $30^{\circ} \mathrm{C}$ and $180 \mathrm{rpm}$. The concentration of copper was measured daily.

In the supernatant metabolites method (spent medium method), $2 \times 10^{6} \mathrm{SFU} / 50 \mathrm{~mL}$ of modified malt extract medium was cultivated for 7 days, then filtrated and adding $0.25 \mathrm{~g}$ of PCBs to the supernatant (filtrate). The concentration of copper was measured daily [22].

\subsubsection{Effect of different parameters on bioleaching of copper from PCBs.}

Four Different culture media summarized as sabouraud dextrose, modified malt-yeast extract, modified Czapek's dox, and modified ammonium media were tested separately with $0.5 \%$ e-waste and inoculation with $2 \times 10^{6} \mathrm{SFU} / 50 \mathrm{~mL}$ medium and incubated at $30{ }^{\circ} \mathrm{C}$. The amount of solubilized copper was measured by titration method, measuring $\mathrm{pH}$ value and redox potential by $\mathrm{pH}$ meter. By applying previous conditions with the best medium, other factors were studied: incubation period, particle size, inoculum size, temperature, pulp density, carbon, nitrogen sources and their concentration, initial $\mathrm{pH}$, and shaking aeration speed.

2.2.4. Mechanism of bio-dissolution of copper from e-waste.

2.2.4.1. Organic acid production.

A. niger exhibits good potential for producing an abundant concentration of organic acids [23]. Therefore, it was tested for acid production by applying it on a petri dish containing Czapek's dox agar medium with $1 \%$ bromocresol green as an organic acid indicator [24] and incubated for 3 days at $30^{\circ} \mathrm{C}$.

2.2.4.2. Detection of some organic acids produced by Aspergillus niger by using HPLC.

Aspergillus niger was grown on modified ammonium medium for three days at $30{ }^{\circ} \mathrm{C}$, added $0.25 \mathrm{~g}$ e-waste $/ 50 \mathrm{~mL}$ medium, and left at $180 \mathrm{rpm}$ for 5 days. The culture filtrate was centrifuged at $9000 \mathrm{rpm}$ for $10 \mathrm{~min}$, then determined citric acid and malic acid by HPLC (YL9100 HPLC System) at Micro Analytical Center, Cairo University. Also, another sample was prepared in the absence of e-waste as a control sample. These organic acids were identified 
by comparison with synthetic organic acids. The last was prepared under the same condition of sample determination.

\subsubsection{The HPLC analysis.}

The HPLC analysis was performed on a clarity chromatography data system; the HPLC system consisted of the Quaternary pump (YL9110 Quaternary Pump), the injection port with a $2 \mathrm{~mL}$ loop, a UV detector (YL9120 UV/Vis Detector), and using Autochrome 3000 software for data acquisition system. For chromatographic separation, a C-18 column (YL9131 Column Compartment) was used. Methanol/water/acetic acid (45:55:5) was used as the mobile phase, and the flow rate was adjusted to $0.8 \mathrm{ml} / \mathrm{min}$. Sample volume $(20 \mu \mathrm{l})$ was injected with the help of a microsyringe, the run time was adjusted to $10 \mathrm{~min}$, and UV absorbance was determined at $260 \mathrm{~nm}$. A synthetic sample of citric and malic acids was used (Sigma). The results obtained from HPLC analysis of the samples were monitored using the abovementioned authentic samples.

\subsubsection{The Scanning electron microscopy (SEM) analysis.}

SEM analysis of e-waste before and after treatment was carried out to show the morphology changes of e-waste. It was carried out by field emission scanning electron microscope using a JEOL instrument QUANTAFEG 250, Netherlands.

\section{Results and Discussion}

\subsection{Chemical composition of waste PCBs.}

By XRF analysis, the chemical analysis of this PCBs sample revealed the presence of high copper content in the sample reached $21.96 \%$, and brome reached $21.96 \%$, then tin reached $16.15 \%$. Other elements such as $\mathrm{Pb}, \mathrm{Zn}, \mathrm{Fe}$, and $\mathrm{Sb}$ were found in small quantities ranging from $8.4 \%$ to $2.6 \%$. In addition to the presence of other elements as $\mathrm{Ba}, \mathrm{Si}, \mathrm{Ca}, \mathrm{Al}, \mathrm{Ni}$, $\mathrm{Sr}$, and $\mathrm{Mg}$. These results were tabulated in Table 1. XRD analysis of PCBs sample was illustrated in Figure 1 and revealed the presence of metallic copper, tin, lead, aluminum, and iron as the main phase constituents.

\begin{tabular}{l|l|l|l|l|l|l|l|l|l|l|l|l|l|l} 
Element & $\mathrm{Cu}$ & $\mathrm{Zn}$ & $\mathrm{Sn}$ & $\mathrm{Fe}$ & $\mathrm{Pb}$ & $\mathrm{Sb}$ & $\mathrm{Ni}$ & $\mathrm{Br}$ & $\mathrm{Ba}$ & $\mathrm{Si}$ & $\mathrm{Sr}$ & $\mathrm{Mg}$ & $\mathrm{Ca}$ & $\mathrm{Al}$ \\
\hline Content (wt. \%) & $\mathbf{2 1 . 9 6}$ & $\mathbf{2 . 6 2}$ & $\mathbf{1 6 . 1 5}$ & $\mathbf{2 . 3 2}$ & $\mathbf{8 . 4 0}$ & $\mathbf{2 . 6 7}$ & $\mathbf{0 . 4 7}$ & $\mathbf{2 1 . 9 6}$ & $\mathbf{1 . 4 1}$ & $\mathbf{0 . 3 5}$ & $\mathbf{0 . 1 4}$ & $\mathbf{0 . 1 0}$ & $\mathbf{0 . 5 0}$ & $\mathbf{0 . 1 6}$
\end{tabular}

Table 1. XRF analysis of WPCBs sample.

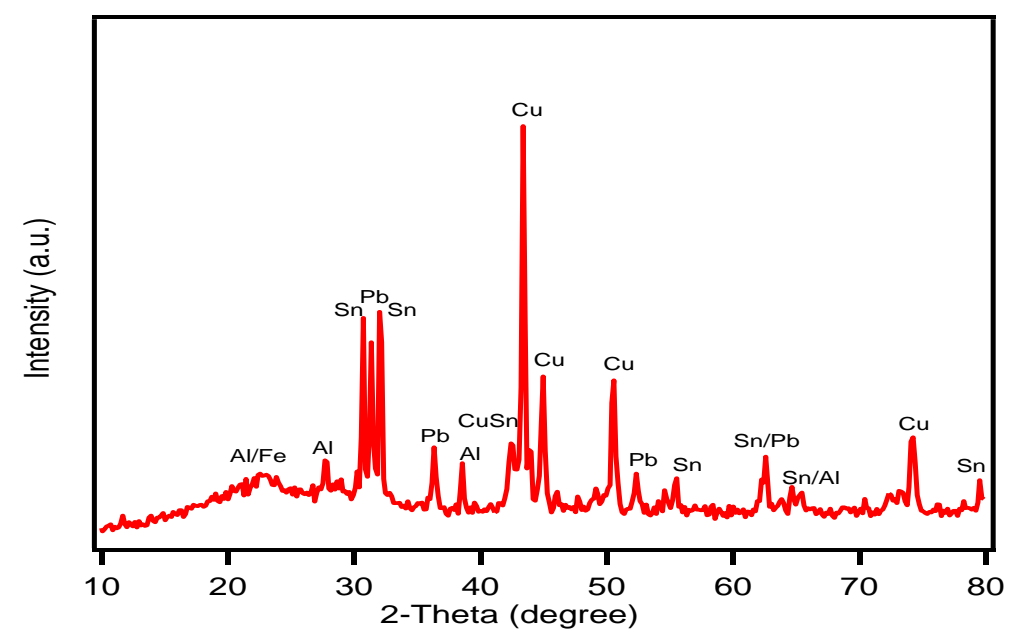

Figure 1. XRD patterns of powdered waste printed circuit boards sample (WPCBs). 


\subsection{Tolerance of Aspergillus niger to various concentrations of copper.}

Various concentrations of copper on the growth of Aspergillus niger were evaluated. The results appeared that optimum growth of Aspergillus niger up to $700 \mathrm{ppm}$ of copper concentration then decreases with increasing concentration of copper up to $1000 \mathrm{ppm}$. This refers to decreasing activity of Aspergillus niger with increasing concentration of copper, as in Table 2 and Figure 2. This confirmed by Nur Liyana Iskandar et al. [25] showed that the growth of $A$. niger decreases with the increasing concentration of copper.

Table 2. The effect of copper concentration on the growth of Aspergillus niger.

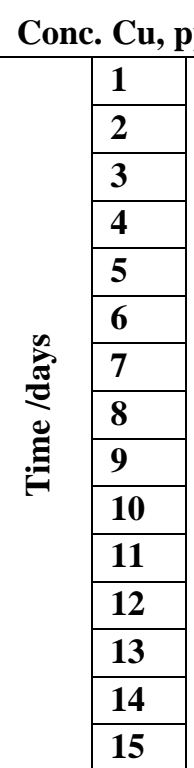

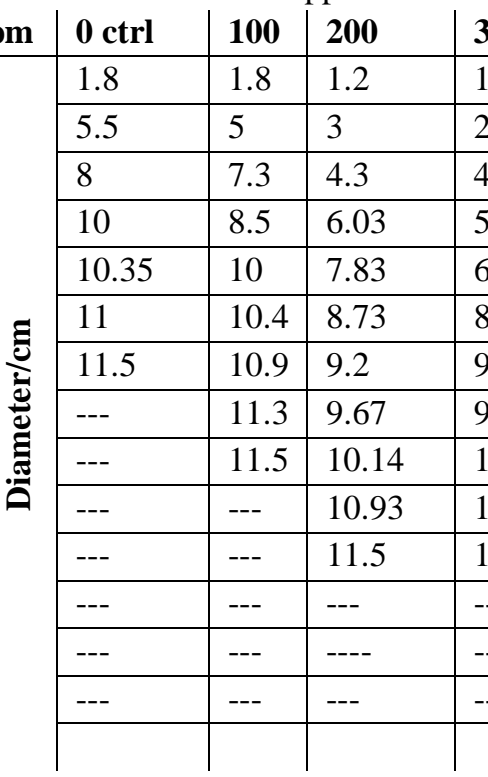

\begin{tabular}{l|l|l|}
$\mathbf{3 0 0}$ & $\mathbf{4 0 0}$ & $\mathbf{5 0 0}$ \\
\hline 1.1 & 1 & 1
\end{tabular}
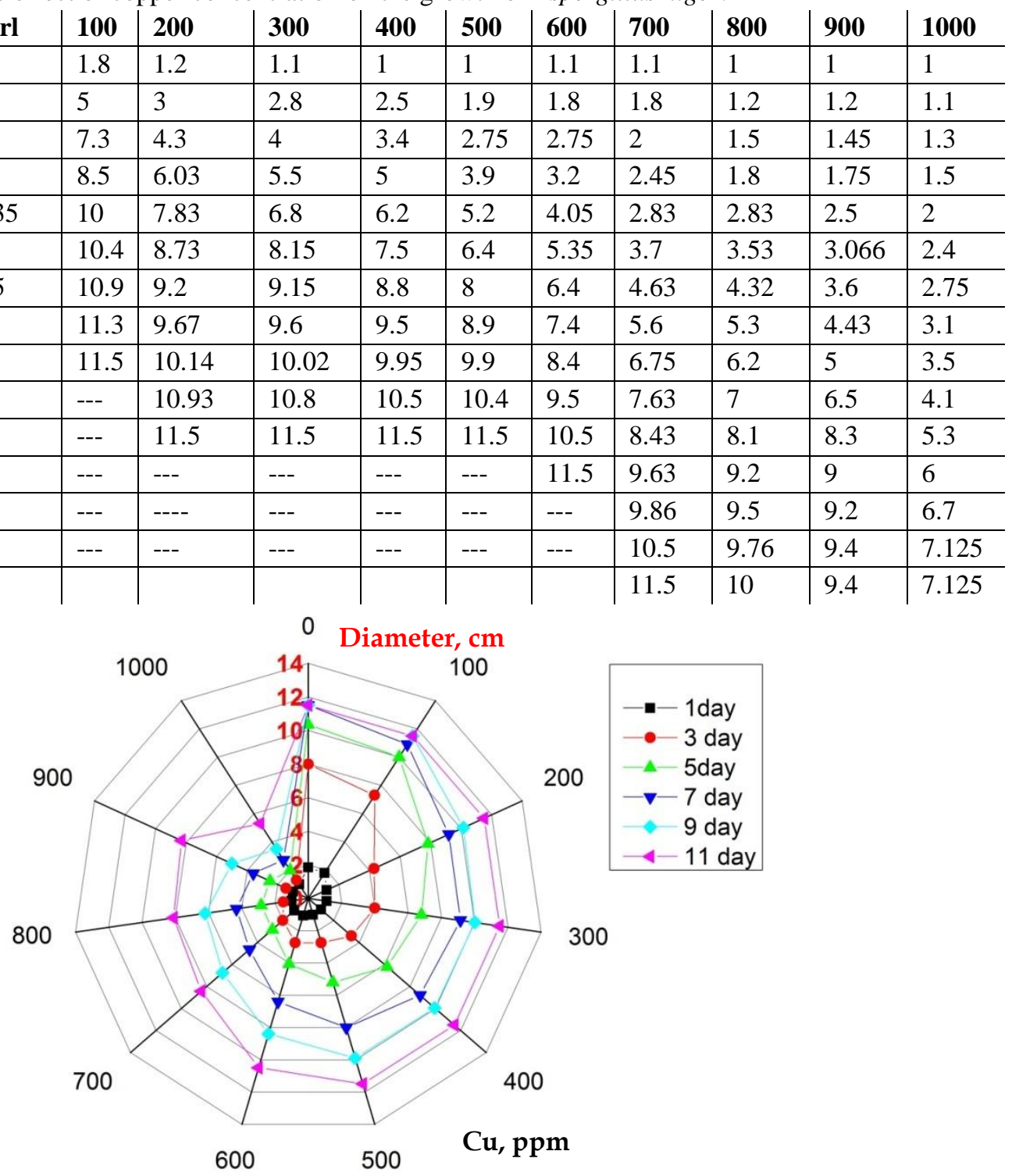

Figure 2. Effect of copper concentration on the growth of Aspergillus niger.

\subsection{Types of bioleaching methods.}

Different bioleaching methods (one-step, two-step, and spent medium) were evaluated by measuring copper concentration with time. The two-step method was preferred over onestep and spent medium, which achieved copper dissolution reached $46 \%$ by using modified malt extract medium. The obtained results were drawn in Figure 3.

In one-step bioleaching, the microorganism was added with e-waste in the medium simultaneously. The growth mechanism in this bioleaching method is the aggregation of 
swollen spores with e-waste particles after inoculation, resulting in relatively large pellet nuclei. Adhesion of un-germinated spores and e-waste particles to the large pellet nuclei contained newly germinated spores also occurred in hyphae, leading to a tendency to reduce the overall number of pellets in the medium. The specific growth rate was decreased as e-waste pulp density increased; this was confirmed by Chauhan and Upadhyay [26], Dey and Jana [27], Grimm et al. [28], and Saravanan et al. [29]. Also, Sadia et al. [30] and Marek et al. [31] showed that the one-step bioleaching was insufficient due to the toxicity of metals present in e-waste that inhibit the growth and activity of Aspergillus niger.

In the two-step bioleaching process, the culturing of Aspergillus niger was prepared for three days, which entered the log phase, then e-waste was added. It was believed to be appropriate to increase the metal leaching efficiency of microorganisms from electronic waste [32]. Microorganisms were grown in the absence of electronic waste to produce biomass, followed by the addition of different concentrations of electronic waste for metal mobilization for an additional period to reduce toxic effects on the microorganisms.

In the spent medium process, the microorganism was removed completely, which may negatively affect a proton production system. The two-step process may be the process of choice for metal bioleaching from e-waste by microorganisms associated with the proton production system [33].

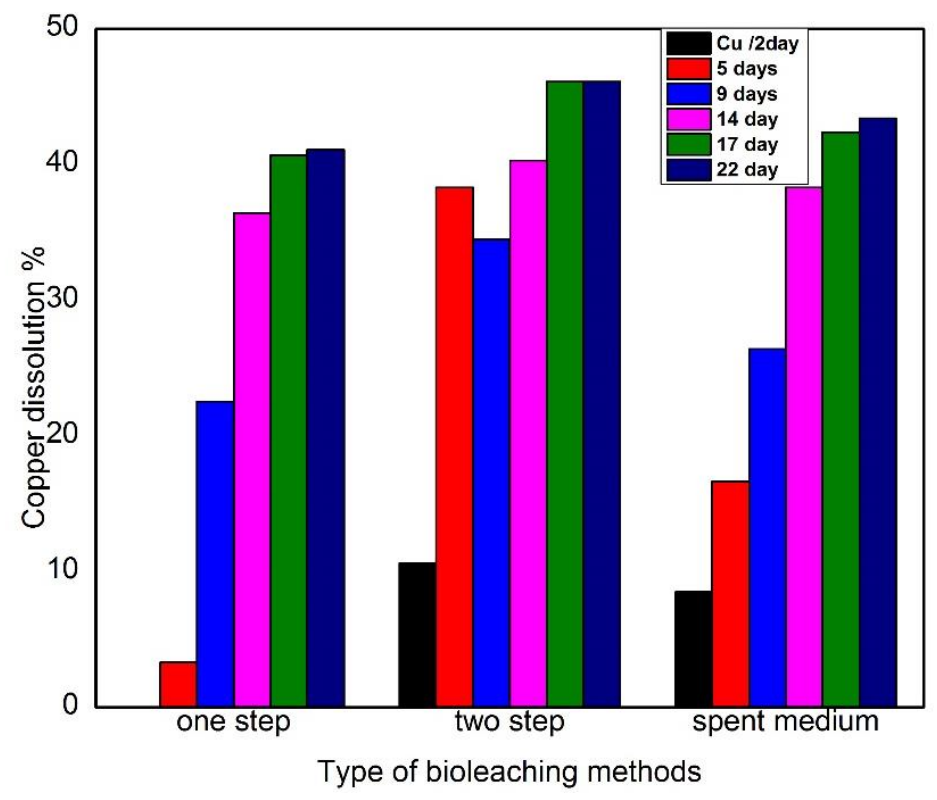

Figure 3. Types of bioleaching methods.

\subsection{Effect of type of media on bioleaching of copper from PCBs.}

Media compositions have a high effect on the growth of microorganisms and the nature of metabolites that are produced, so it is preferred to test various media (Sabouraud Dextrose, modified malt-yeast extract, modified Czapek's Dox modified ammonium medium) to select the best medium utilized by microorganism for copper dissolution. The culture of $2 \times 10^{6}$ $\mathrm{SFU} / 50 \mathrm{ml}$ medium was prepared for 3 days, then $0.25 \mathrm{~g}$ of e-waste was added and incubated at $30^{\circ} \mathrm{C}$ and $180 \mathrm{rpm}$. The copper dissolution, $\mathrm{pH}$, and redox potential were measured daily.

The results revealed that the best medium for dissolution of copper was modified ammonium medium, which dissolved $98.5 \%$ of copper at $\mathrm{pH} 4.1$ and redox potential 167 after 5 days of incubation, while the minimum copper dissolution occurred with sabouraud dextrose medium, although the $\mathrm{pH}$ of the medium was lower than modified ammonium medium, Figure 
4. The biomass of Aspergillus niger in the sabouraud dextrose medium was very large, this leads to aggregation of particles of e-waste with biomass, and this reduces the dissolution process. Mostafa and Alamri [34] showed that the optimum composition of the medium for citric acid production by Aspergillus niger strain $\mathrm{AB} 1801$ were $15 \mathrm{~g} / \mathrm{l}$ sucrose, $0.22 \% \mathrm{NH}_{4} \mathrm{NO}_{3}$, $0.1 \mathrm{~g} / 1 \mathrm{~K}_{2} \mathrm{HPO}_{4}, 0.02 \% \mathrm{MgSO}_{4} .7 \mathrm{H}_{2} \mathrm{O}, 0.0001 \% \mathrm{FeSO}_{4} .7 \mathrm{H}_{2} \mathrm{O}, 0.0001 \mathrm{~g} / 1 \mathrm{ZnSO}_{4} .7 \mathrm{H}_{2} \mathrm{O}, 0.0001$ $\mathrm{g} / \mathrm{MnSO} 4.4 \mathrm{H}_{2} \mathrm{O}, \mathrm{pH}$ 3.5. Also, Male et al., [23]; Falguni and Lakshmi, [35]; Castro et al., [36]; Sadia et al., [30] showed that acidification of the medium during the growth of A. niger is due to the excretion of organic acids that led to decreasing $\mathrm{pH}$ of the medium. These organic acids were necessary for the dissolution process.

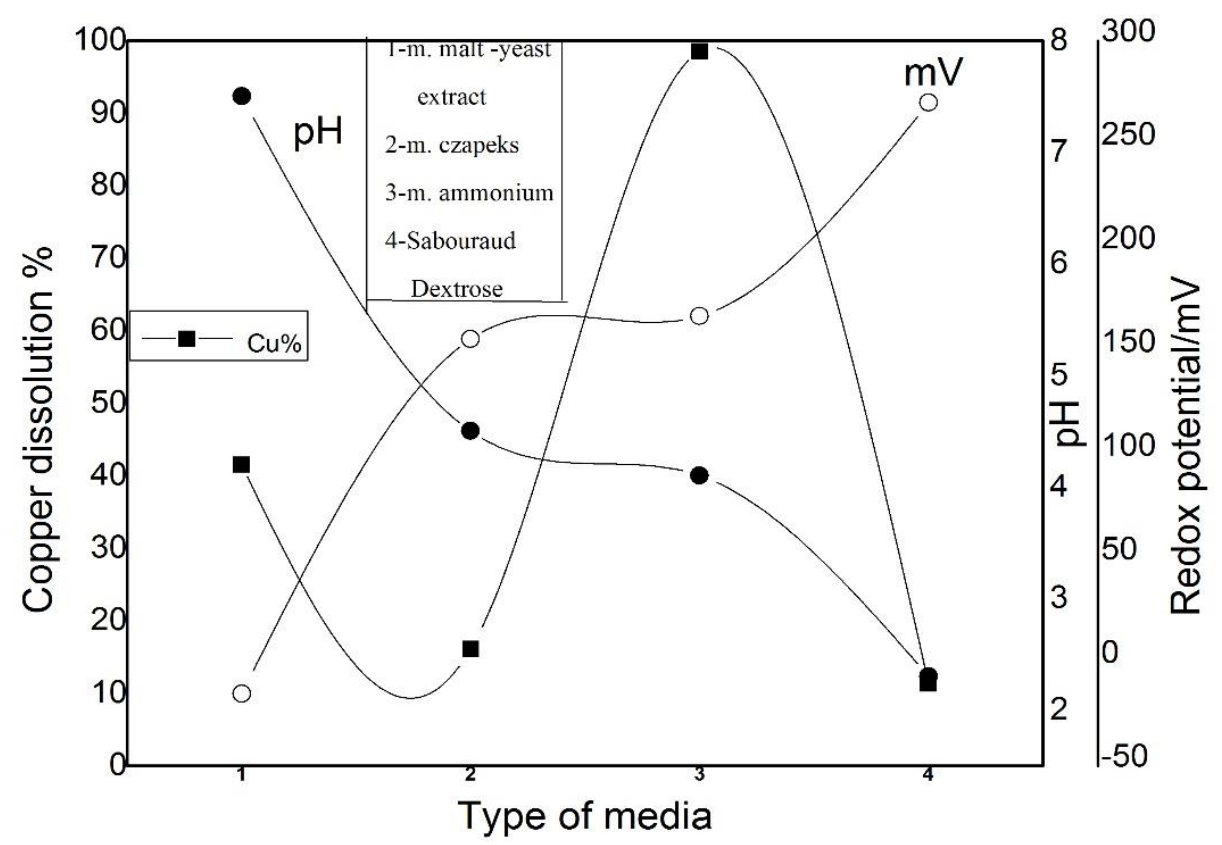

Figure 4. The effect of type of media on bioleaching of copper by A. Niger.

\subsection{Effect of incubation period on copper dissolution by Aspergillus niger.}

$50 \mathrm{~mL}$ modified ammonium medium was prepared for culturing $2 \times 10^{6} \mathrm{SFU}$ of Aspergillus niger for 3 days then $0.25 \mathrm{~g}$ of +150 mesh of e-waste was added and incubated at $30^{\circ} \mathrm{C}$ and $180 \mathrm{rpm}$. The copper dissolution, $\mathrm{pH}$, and redox potential were measured daily to determine the optimum incubation period.

The results were revealed that the maximum biodissolution of copper occurred after 5 days of incubation, which reached $97.7 \%$ with $\mathrm{pH}$ value 4.2 and redox potential $185.3 \mathrm{mV}$, Figure 5. Yaashikaa et al., [37]; Liang et al., [38]; Wang et al., [39] showed that Cu bioleaching efficiencies vary widely from $50 \%$ to $100 \%$ with leaching periods typically exceeding 5 days. Grewal and Kalra [40] reported that the medium $\mathrm{pH}$ decreased from 6 to 4.6, indicating that the fungus was in its logarithmic growth phase and secretion of organic acids had begun. The maximum overall production of organic acids, i.e., 5237 ppm citric acid, 3666 ppm gluconic acid, $1287 \mathrm{ppm}$ oxalic acid, and $188 \mathrm{ppm}$ malic acid was observed on the 15th day of fungal growth. At lower $\mathrm{pH}$ values, gluconic and citric acids are the major products. Hassan et al. [41] showed that higher fermentation periods led to acid consumption by the fungus due to lack of nutrients in the culture. 


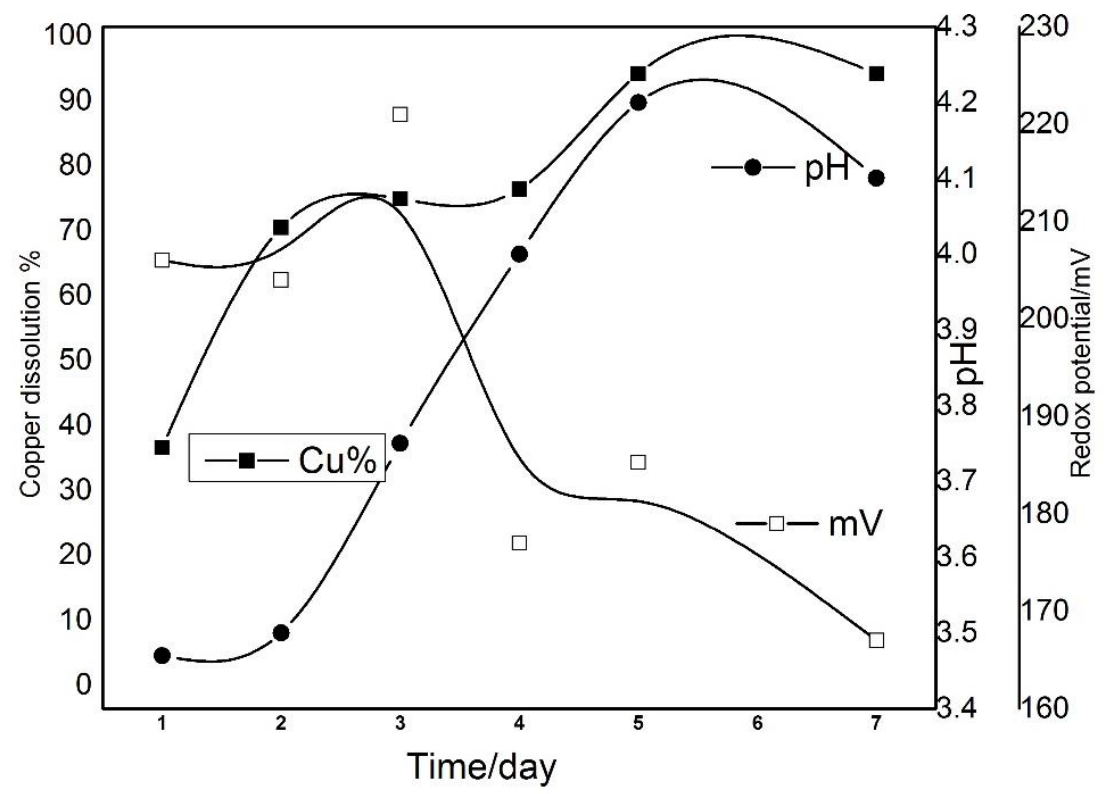

Figure 5. The effect of incubation period on copper dissolution by Aspergillus niger.

\subsection{The effect of particle size factor on copper dissolution by Aspergillus niger:}

Different size fractions of e-waste $(20,50,150$, and -150 mesh) were tested for copper dissolution. In these experiments, $0.25 \mathrm{~g}$ of e-waste for $50 \mathrm{ml}$ of culturing of $2 \times 10^{6} \mathrm{SFU}$ of Aspergillus niger was used and incubated at $30^{\circ} \mathrm{C}$ and $180 \mathrm{rpm}$. The copper dissolution, $\mathrm{pH}$, and redox potential were measured after 5 days of incubation.

The obtained results revealed that dissolution of copper increased with decreasing size fraction up to +150 mesh at which $97.9 \%$ of copper dissolved with $\mathrm{pH} 4.01$ and redox potential $176 \mathrm{mV}$ as in Figure 6.

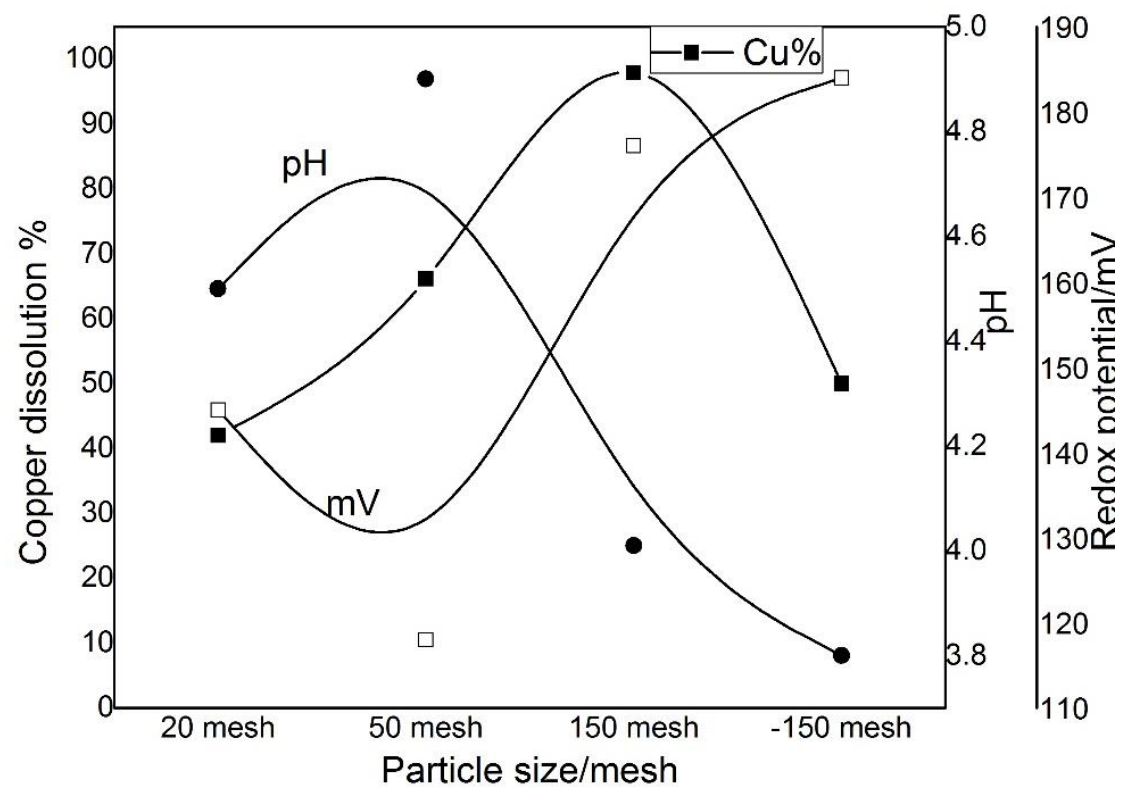

Figure 6. The effect of particle size factor on copper dissolution by A. niger.

Decreasing size fraction over +150 mesh led to decreased copper dissolution due to aggregation of e-waste particles and decreased interaction with A. niger. Patel confirmed this; Lakshmi [42] showed that particle size negatively correlates with metal leaching efficiency, and large particle sizes may lead to low metal extraction efficiency. The surface area increases with decreasing particle size, leading to the contact between the metal-bearing waste particles and the leachant in the medium, increasing and increasing metal extraction efficiency. Also, 
$\mathrm{Wu}$ et al. [43] showed that in the bio-hydrometallurgical process, microbial cells contact the waste particles, leading to the metal leaching efficiency and bioleaching rate in biohydrometallurgical processes.

\subsection{The effect of inoculum size of Aspergillus niger on copper dissolution.}

Different inoculum sizes of Aspergillus niger $\left(1 \times 10^{6}, 2 \times 10^{6}, 4 \times 10^{6}, 6 \times 10^{6}, 8 \times 10^{6}\right) \mathrm{SFU}$ were inoculated to $50 \mathrm{ml}$ modified ammonium medium for 3 days then added $0.25 \mathrm{~g}$ of e-waste and measuring copper dissolution, $\mathrm{pH}$, and redox potential after 5 days.

The obtained results revealed that dissolution of copper increased with increasing inoculum size up to $2 \times 10^{6} \mathrm{SFU}$ for $50 \mathrm{~mL}$ medium, then began to decrease with increasing inoculum size, Figure 7. At using $2 \times 10^{6} \mathrm{SFU}$, copper dissolution reached $97.9 \%$ with $\mathrm{pH} 4.27$ and redox potential $160.9 \mathrm{mV}$, and this refers to an increasing number of cells up to a certain limit lead to increase production of metabolites that necessary to leaching of copper, but a higher number of cells lead to competition on nutrients in medium and effect on the production of metabolites and decrease dissolution rate. The bioleaching rate increases with increasing inoculum size; it has been reported in bioleaching of metals by various researchers (Minimol et al., [44], Weihua et al. [45], Denaya et al. [46]).

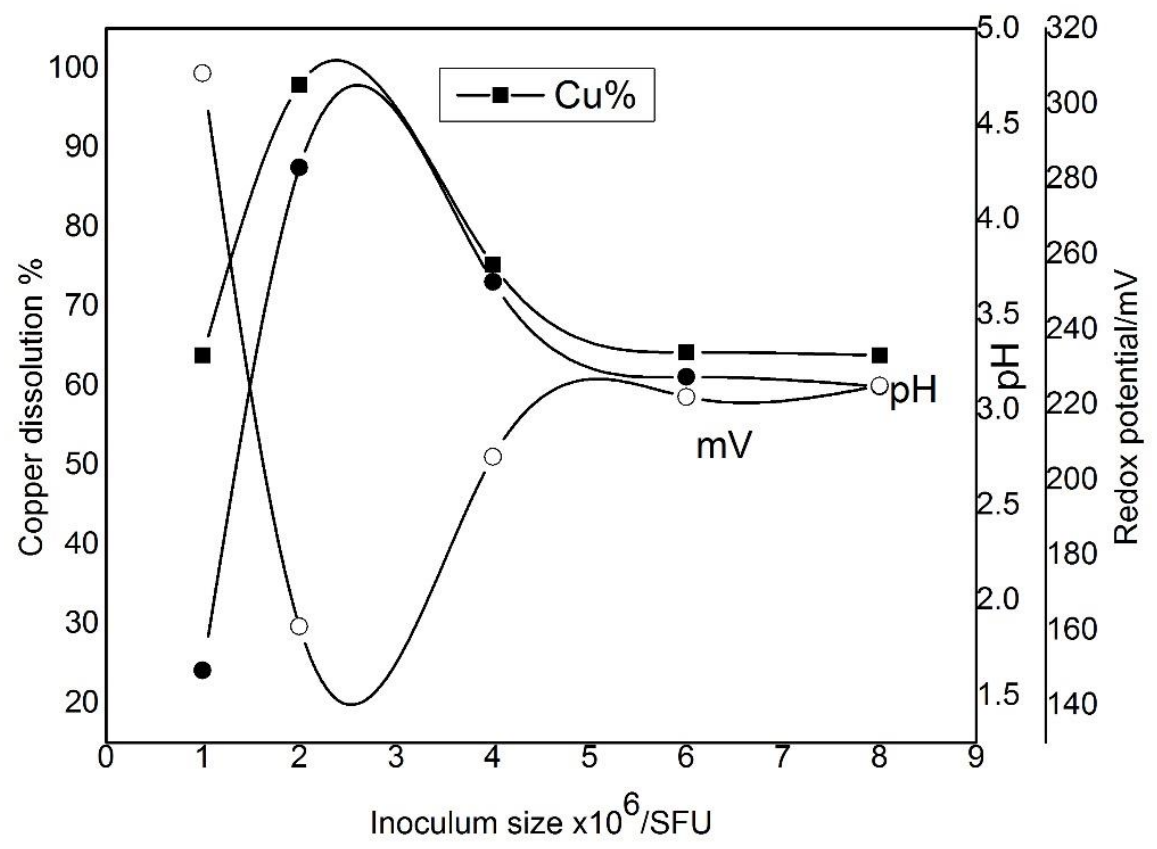

Figure 7. The effect of inoculum size of A. Niger on copper dissolution.

Maria and Michael [47] showed that lower dissolved oxygen levels at much higher inoculums levels during the early fermentation phase were related to slower ammonium ions uptakes and significantly lower glucosamine concentrations, so the dissolution process decreased.

\subsection{The effect of incubation temperature on copper dissolution by A. Niger.}

Temperature is an important factor that affects the activity of microorganisms. Different incubation temperatures $(25,30,35,40){ }^{\circ} \mathrm{C}$ were tested by applying the predetermined conditions and measuring copper dissolution, $\mathrm{pH}$, and redox potential after 5 days of incubation. The results revealed that copper dissolution increased with increasing temperature up to $30{ }^{\circ} \mathrm{C}$ then began to decrease, which reached $97.8 \%$ with $\mathrm{pH} 4.12$ and redox 
potential $162 \mathrm{mV}$, Figure 8 . This refers to optimum A. niger activity was at $30{ }^{\circ} \mathrm{C}$ that produces more efficient metabolites used in copper dissolution.

Saidan et al. [48] showed that incubation temperature is a vital environmental factor that can affect the biodissolution of e-wastes by affecting both the biological activity and chemical leaching of e-waste.

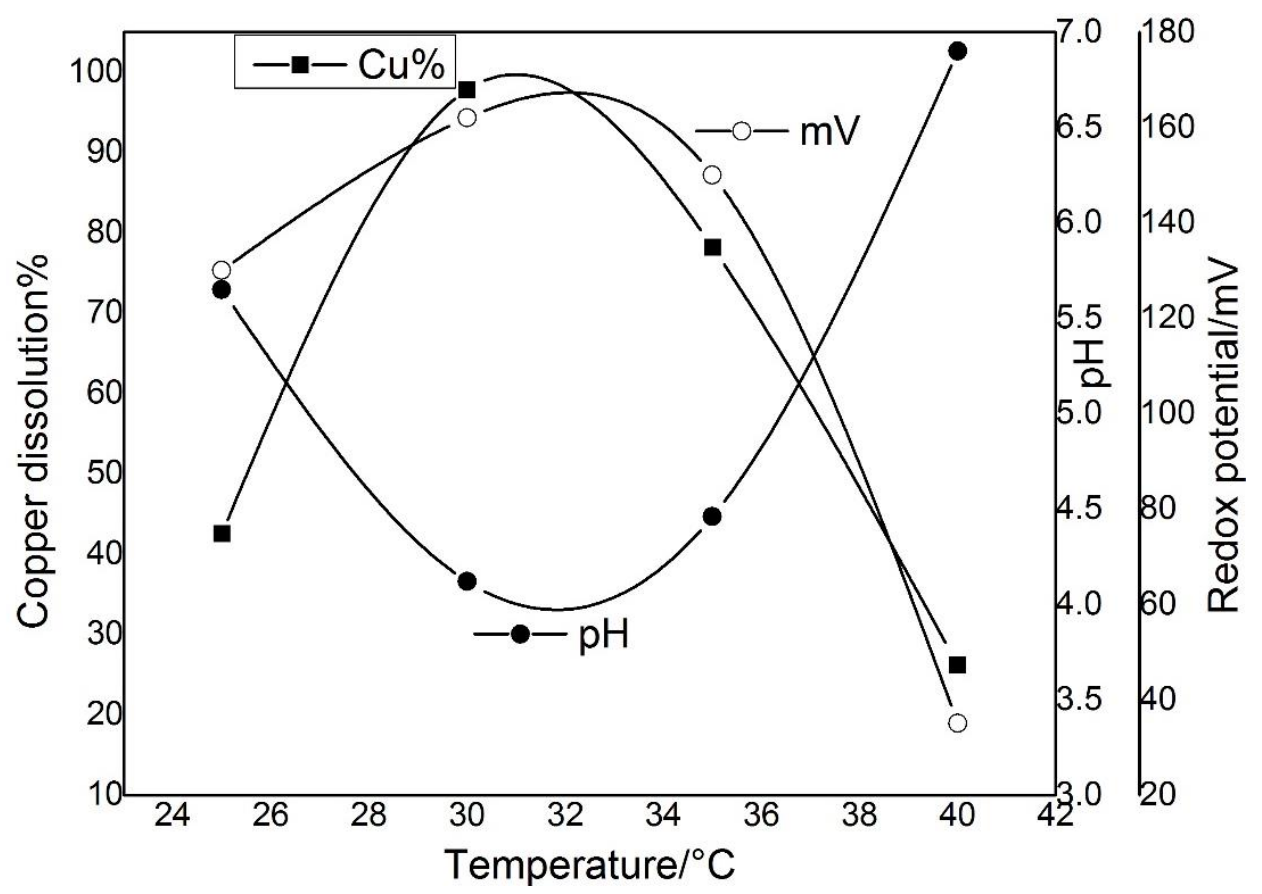

Figure 8. The effect of incubation temperature on copper dissolution by A. niger.

\subsection{The effect of pulp density on copper dissolution by A. niger.}

Different weights of e-waste $(0.1,0.25,0.5$, and 0.75$) \mathrm{g}$ for $50 \mathrm{ml}$ of medium were evaluated by applying predetermined conditions, then measuring copper dissolution, $\mathrm{pH}$, and redox potential after 5 days of incubation.

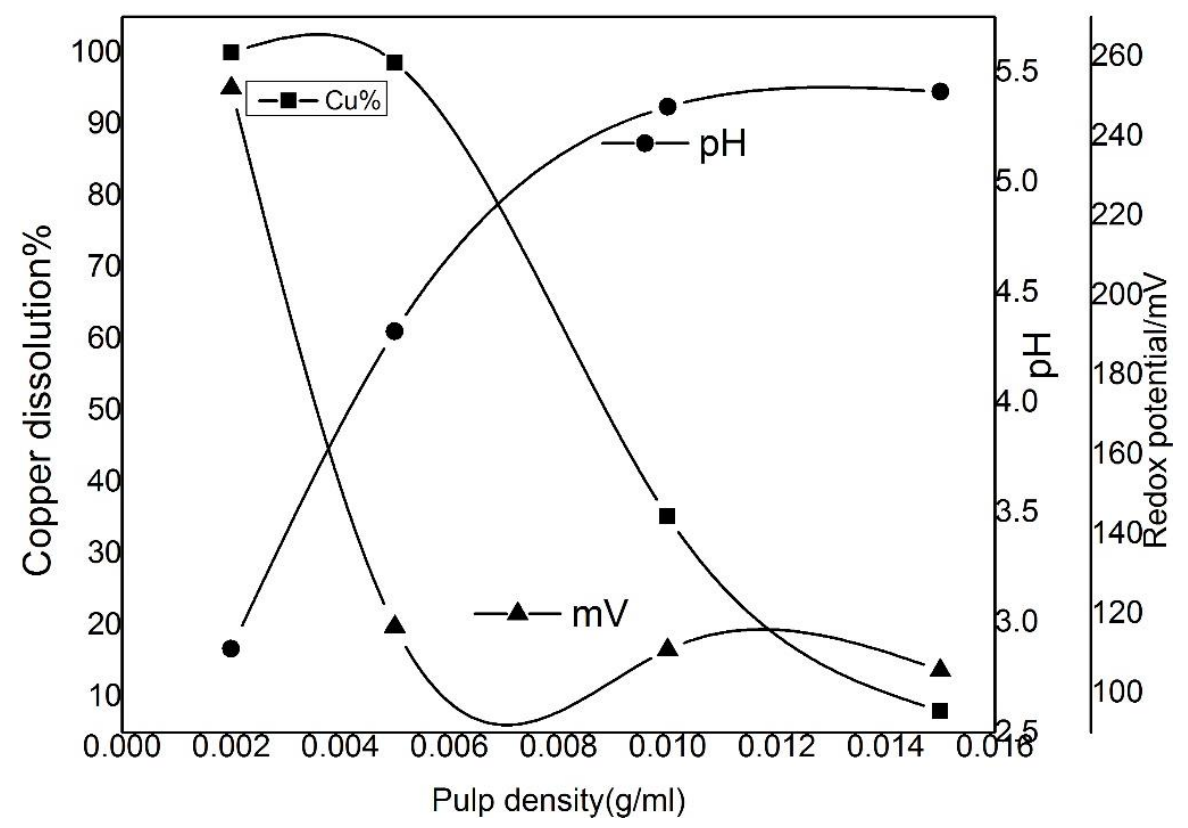

Figure 9. The effect of pulp density on copper dissolution by A. niger.

It was found that increasing pulp density led to a decrease in the dissolution of copper. This is attributed to an increase in metals concentration, leading to a decrease in A. niger 
activity and effect on the produced metabolites and acids. At pulp density $0.005 \mathrm{~g} / \mathrm{ml}$, Aspergillus niger can solubilize $98.6 \%$ of copper with $\mathrm{pH} 4.32$ and redox potential $116.59 \mathrm{mV}$, Figure 9, and this refers to the presence of organic acid used in the dissolution process.

Also, Sadia et al. [30], Erüst et al. [49] showed that metal leaching efficiencies decrease significantly with increasing pulp density. This can be due to the alkaline nature of the e-waste material and is therefore acid-consuming. This leads to a high $\mathrm{pH}$ environment, where the acidophiles do not thrive. Also, high pulp density is desired for the economic leaching of metals, but it has inhibitory effects on the microorganisms, which decrease the bioleaching processes [50].

\subsection{Effect of different carbon sources on copper dissolution by A. niger.}

Carbon source is a vital factor for the active proliferation of microorganisms and the production of organic acids. Different carbon sources (starch, sucrose, glucose, dextrose, lactose) were tested by applying predetermined conditions and measuring dissolution of copper, $\mathrm{pH}$, and redox potential after 5 days of incubation. The results showed that glucose's best carbon source was glucose, which achieved maximum biodissolution of copper $100 \%$ with $\mathrm{pH} 4.25$ and redox potential $173 \mathrm{mV}$, Figure 10.

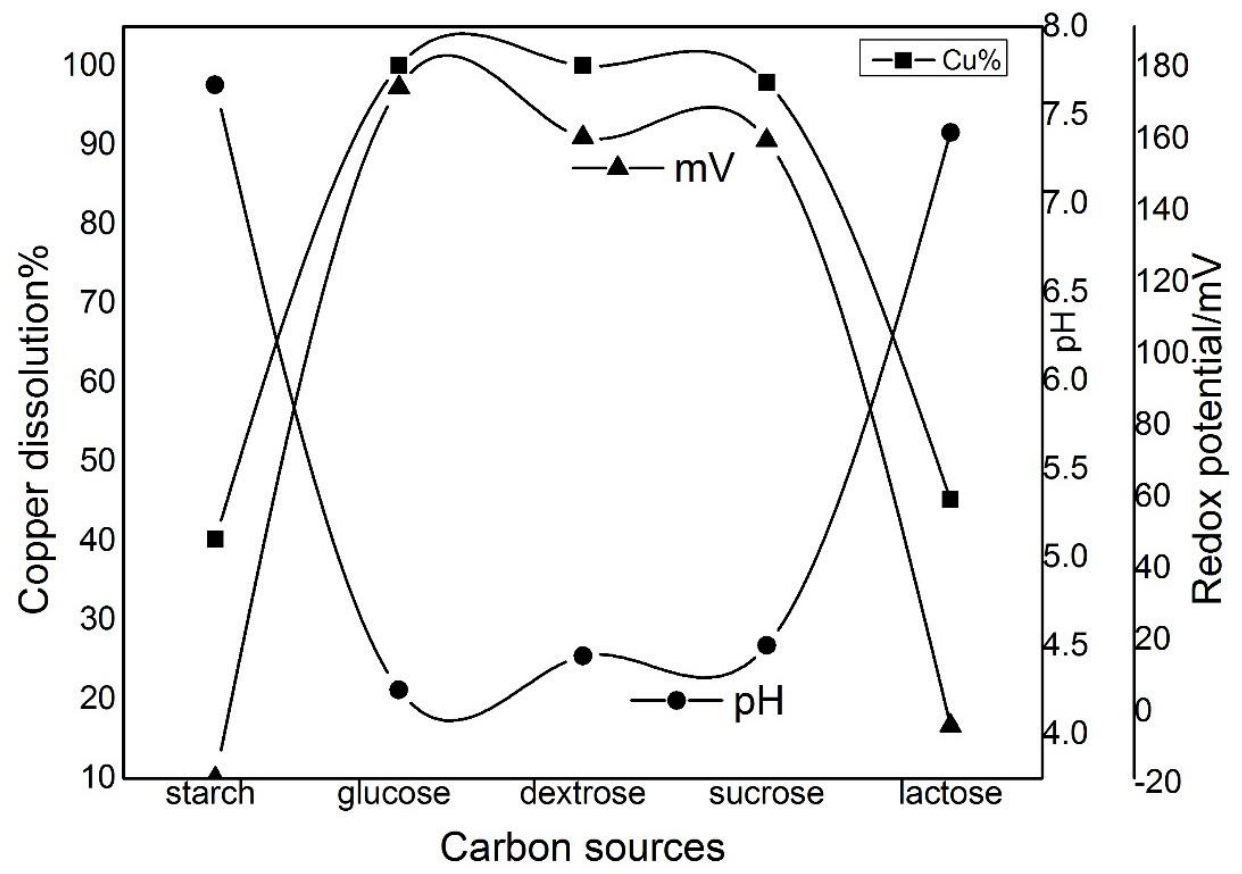

Figure 10. Effect of different carbon sources on copper dissolution by A. niger.

Sugars in media are converted into intermediate metabolites, including organic acids and other substances by enzymes produced by the microorganism. Enzyme systems are different from one microorganism to another. The metabolic pathway and the types of organic acids produced by microorganisms result from the regular metabolic routes or the type of carbon source used [51]. These results disagree with Luciana et al., [52], who showed That sucrose is a better carbon source for A. niger than glucose due to the higher production of citric acid used in the dissolution process.

\subsection{Effect of different carbon concentrations on copper dissolution by A. niger.}

$2 \times 10^{6}$ of Aspergillus niger was inoculated to $50 \mathrm{~mL}$ modified ammonium medium for 3 days with the presence of different concentrations of glucose as carbon source $(0.01,0.015$, 
$0.02,0.025,0.03)$ then added $0.25 \mathrm{~g}$ of +150 mesh of e-waste and incubated at $30{ }^{\circ} \mathrm{C}$. The dissolution of copper, $\mathrm{pH}$, and redox potential were measured after 5 days of incubation.

The results showed that copper dissolution increased with increasing glucose concentration reaching nearly $100 \%$ at $0.02 \mathrm{~g} / \mathrm{ml}$ glucose concentration. Further increase in glucose concentration does not affect copper dissolution (remain constant around 100\%), Figure 11. The carbon concentration is the effect on the growth of A. niger and so production of metabolites, especially organic acids, that is important for the dissolution process.

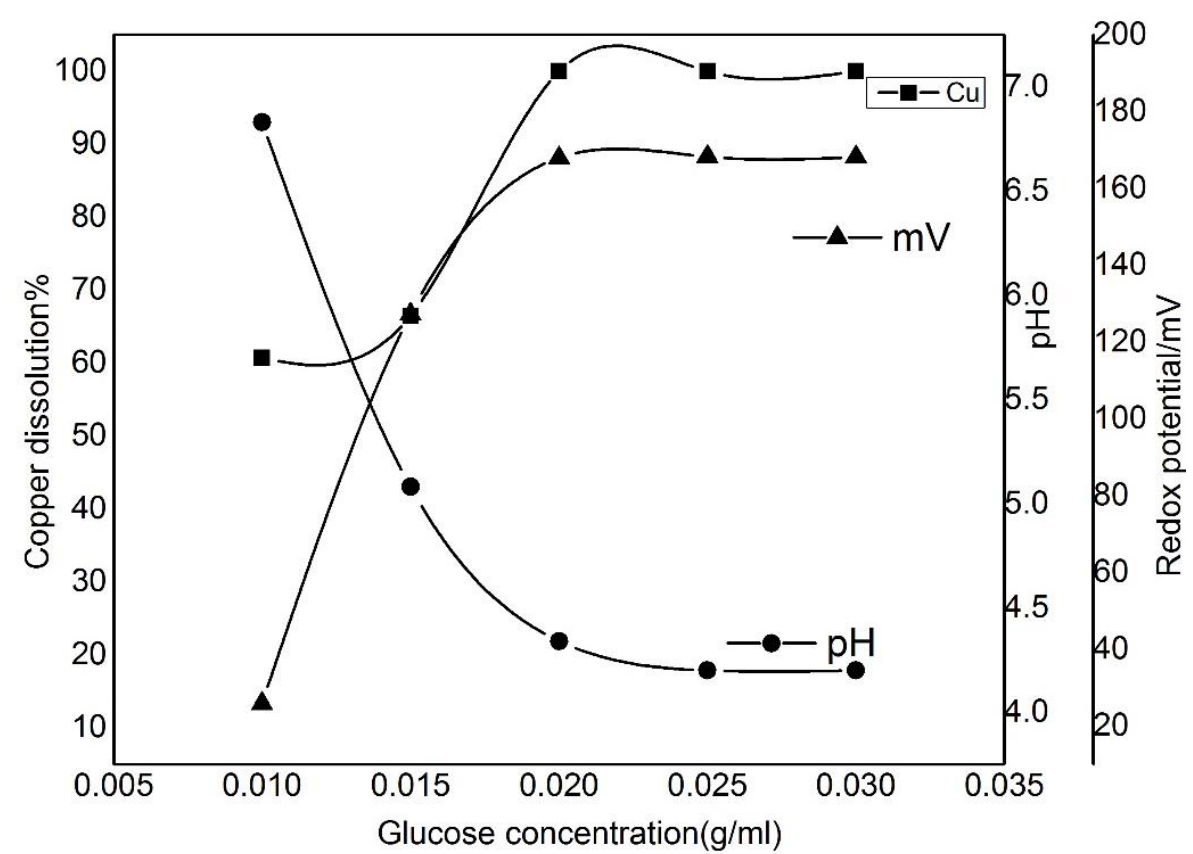

Figure 11. Effect of different carbon concentrations on copper dissolution by A. niger.

\subsection{Effect of different nitrogen sources on copper dissolution by A. niger.}

Different nitrogen sources (ammonium sulfate, ammonium chloride, ammonium phosphate, and asparagine) were tested for copper dissolution at the predetermined conditions and measuring dissolution of copper, $\mathrm{pH}$, and redox potential after 5 days of incubation.

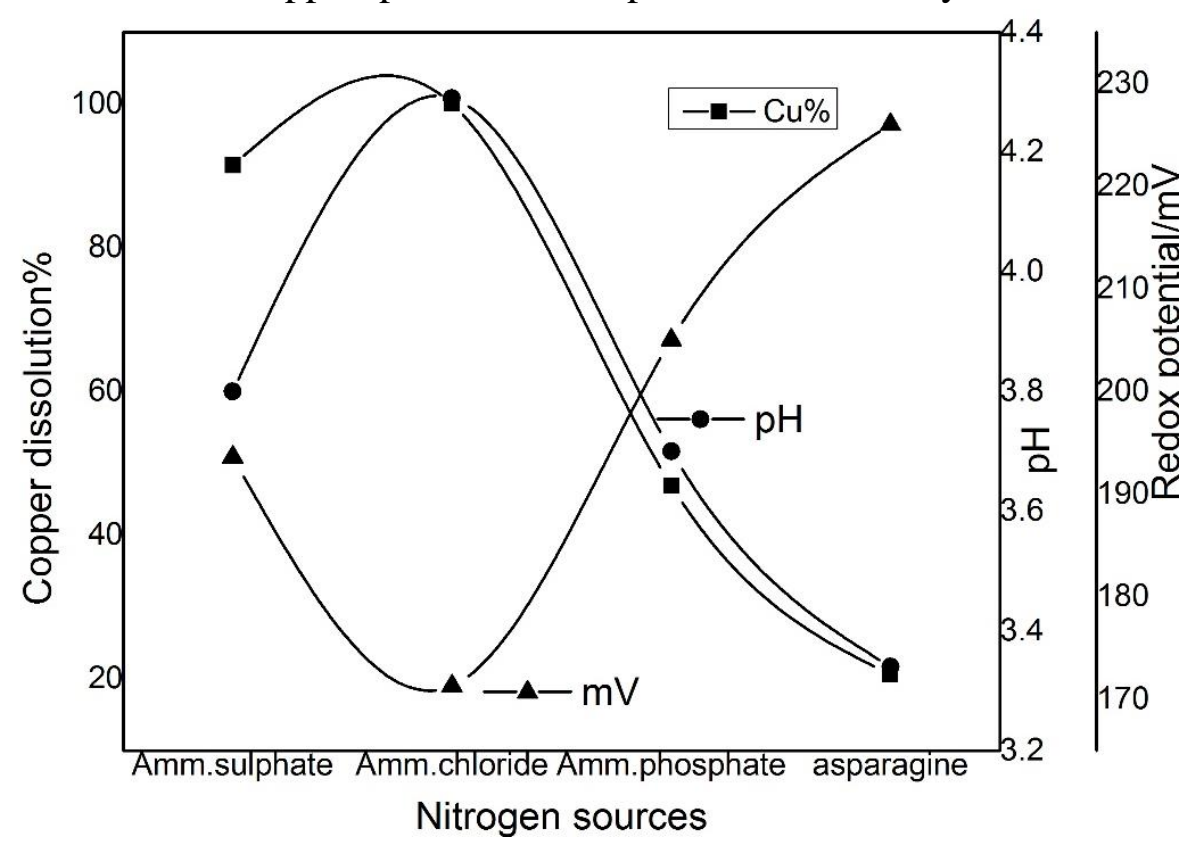

Figure 12. Effect of different nitrogen sources on copper dissolution by A. niger. 
The obtained results revealed that the best nitrogen source was ammonium chloride that achieved copper dissolution $100 \%, \mathrm{pH} 4.29$, and redox potential $171.3 \mathrm{mV}$, as shown in Figure 12. This refers to ammonium chloride as the best nitrogen source for the optimum growth of Aspergillus niger and more metabolites used in the dissolution process. The lowest copper dissolution was occurred by using asparagine as a nitrogen source that can have an inhibition effect on the growth of Aspergillus niger. This agrees with Bikash [53], who showed that ammonium is the most widely used nitrogen source for citric acid production in A. niger.

\subsection{Effect of different concentrations of nitrogen source on copper dissolution by A. Niger.}

Different ammonium chloride concentrations $(0.001,0.0015,0.002,0.0025) \mathrm{g} / \mathrm{mL}$ were tested by applying predetermined conditions and measuring dissolution of copper, $\mathrm{pH}$, and redox potential after 5 days of incubation.

The results revealed that the copper dissolution increased with increasing nitrogen concentration reaching $100 \%$ at $0.002 \mathrm{~g} / \mathrm{mL}, \mathrm{pH} 4.12$, and redox potential $182.5 \mathrm{mV}$, then remained constant. The results were drawn in Figure 13. The $0.002 \mathrm{~g} / \mathrm{mL}$ was the best concentration of ammonium chloride for optimum growth of Aspergillus niger to produce more metabolites used in the dissolution process.

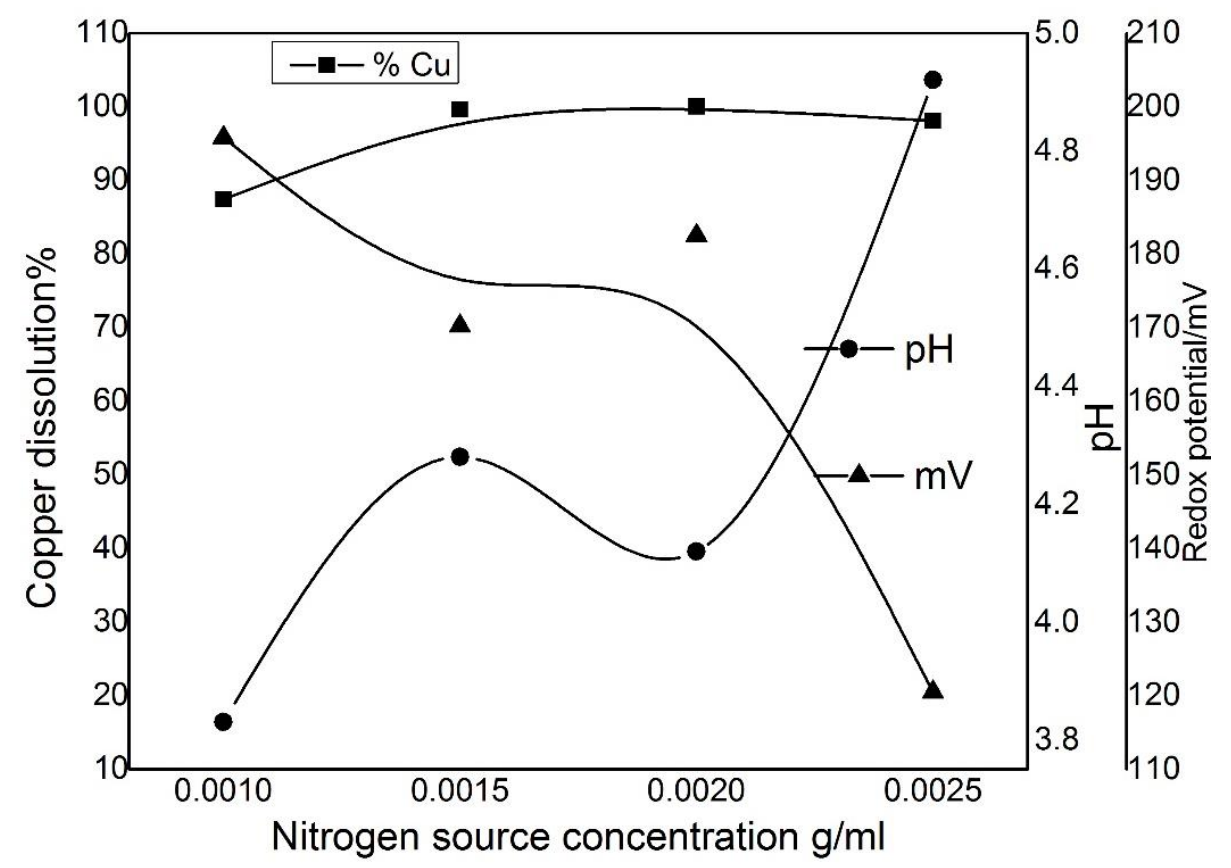

Figure 13. Effect of different nitrogen source concentrations on copper dissolution by A. niger.

This result disagrees with Varsha [54], who showed that any increase or decrease other than ammonium sulfate $(0.25 \% \mathrm{w} / \mathrm{v})$ and ammonium chloride $(0.5 \% \mathrm{w} / \mathrm{v})$ concentration resulted in the disturbance of fungal growth and subsequently citric acid production.

\subsection{Effect of different initial pH on copper dissolution by A. Niger}

Different initial $\mathrm{pH}(4,5,7,8$, and 9) of medium were tested with predetermining conditions and dissolution of copper, $\mathrm{pH}$, and redox potential after 5 days of incubation.

The results revealed that the best initial $\mathrm{pH}$ of the medium was 7 , at which $100 \%$ copper dissolution, $\mathrm{pH} 4.12$, and redox potential $182.6 \mathrm{mV}$. These results were drawn in Figure 14. The $\mathrm{pH}$ of the solution is one of the most important factors for (bio) leaching processes. For 
example, while the citric acid (maximum $\sim 60 \mathrm{mM}$ ) is produced more efficiently under acidic conditions ( $\mathrm{pH} 3$ ), the optimum for gluconic acid production is at a $\mathrm{pH}$ of $4.5-6.5$, which refers to glucose oxidase activity enzymes. Aspergillus niger produces high concentrations of organic acids that contribute to the acidification of culture media [54].

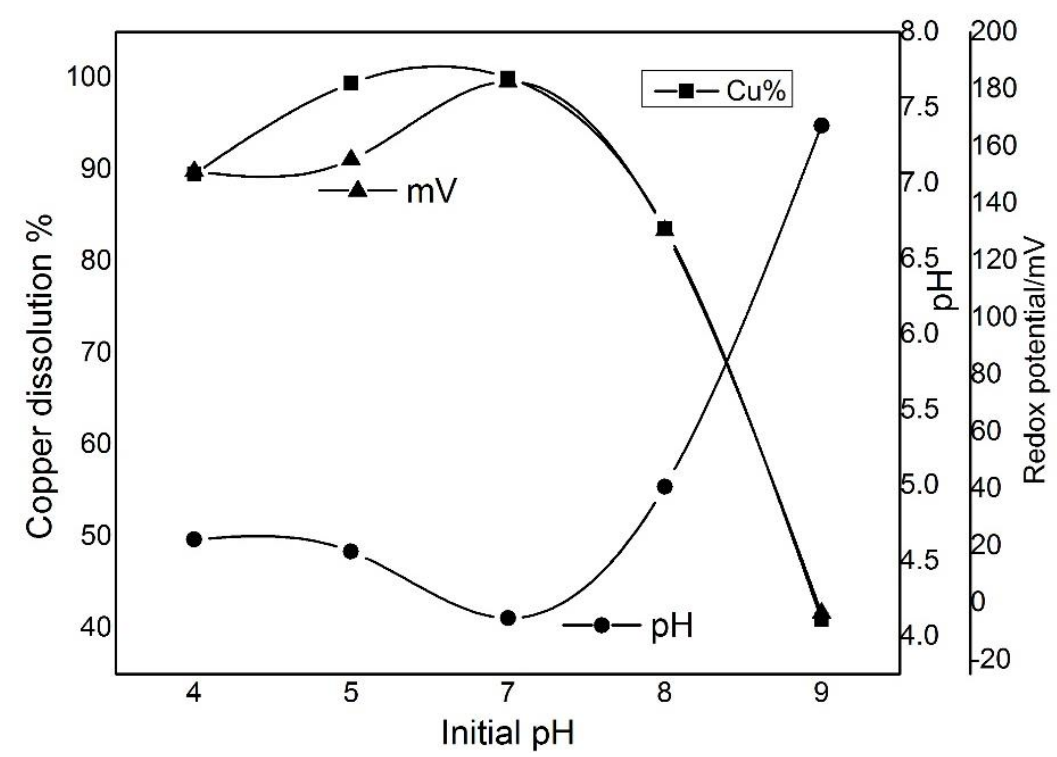

Figure 14. Effect of different initial $\mathrm{pH}$ on copper dissolution by A. niger.

\subsection{Effect of aeration on copper dissolution by A. Niger.}

Different shaking speeds $(100,150,200,250) \mathrm{rpm}$ were tested with predetermining conditions and dissolution of copper, $\mathrm{pH}$, and redox potential after 5 days of incubation.

The results revealed that copper dissolution increased with increasing shaking speed up to $200 \mathrm{rpm}$ and then decreased with increasing shaking speed. At $200 \mathrm{rpm}$, copper dissolution reached $100 \%, \mathrm{pH} 4.15$ and redox potential $181.6 \mathrm{mV}$, Figure 15. Agitation can affect the production of types and concentration of metabolites medium and affect $\mathrm{pH}$ values of medium and leaching efficiency [30].

Also, this agrees with Hacıfazlıoğlu et al., [55], who found that neither high nor low agitation speeds were suitable for the growth of A. niger and the production of metabolites.

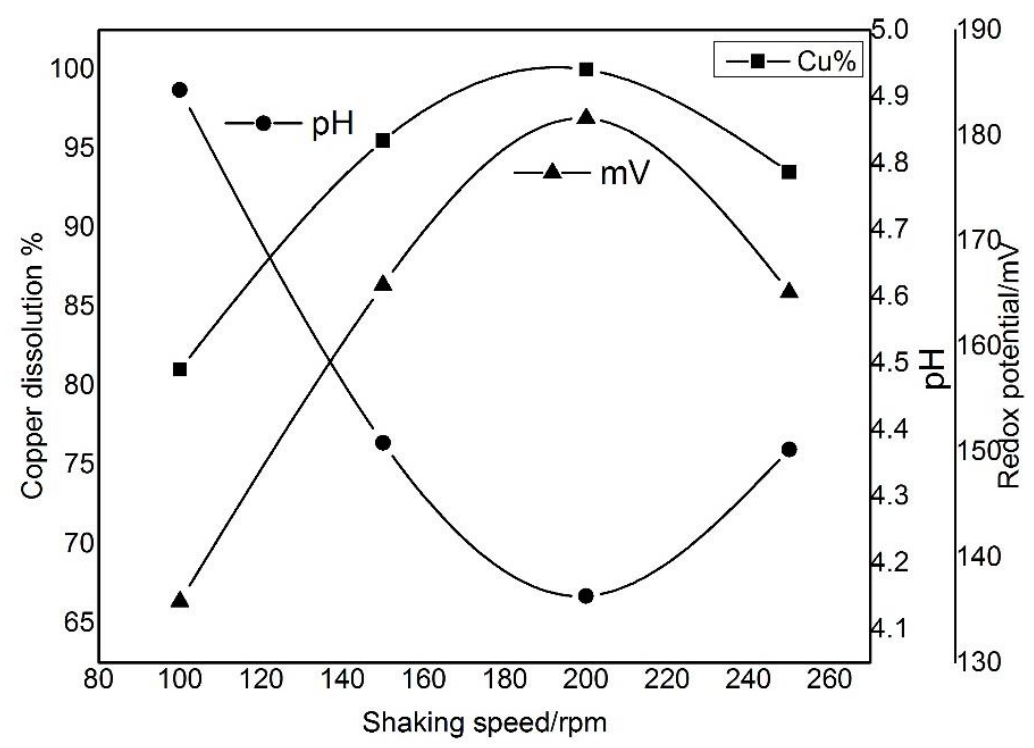

Figure 15. Effect of aeration on copper dissolution by A. niger. 


\subsection{Mechanism of bioleaching of copper by A. niger.}

There were several mechanisms of bioleaching of copper by Aspergillus niger, including secretion of enzymes as glucose oxidase enzyme [54]. Aspergillus niger can produce chelators such as siderophores [56]that chelate calcium, aluminum, and iron. Also, it can produce organic acids by fermentation of glucose as a carbon source. This is considered to be the most important mechanism of bioleaching of copper by Aspergillus niger that produced it in a high amount [57].

Organic acids production can be tested by using bromocresol green as an acid indicator (1\%) added to Czapek's agar on the plate at $\mathrm{pH}$ 6. It was observed that change the color from blue to yellow with the growth of Aspergillus niger on a plate, which refers to the production of organic acids as illustrated in Figure 16. This accepts by Alessia et al. [58].
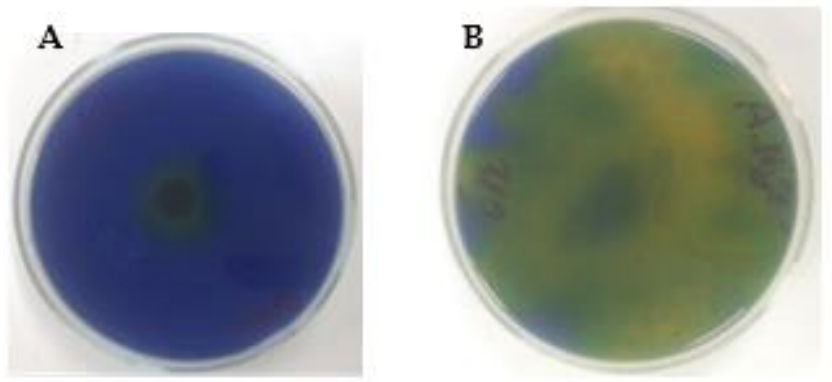

Figure 16. Cultivation of $A$. niger for 2 days (A), cultivation of A. niger for 7 days (B).

Hydrogen ions of organic acids produced by Aspergillus niger can replace metal cations from the e-waste matrix and lead to metal leaching. Secondly, organic acids make chelation for metals and form soluble metal-ligand complexes. Organic acids are less toxic to many biological communities than inorganic acids due to their capacity to reduce toxic metal concentrations.

Organic acids are biologically degradable [59]. The metal leaching by organic acids can be carried out under mildly acidic conditions ( $\mathrm{pH} 3-5$ ) [60]. Microbiological production for organic acids is an important economic alternative to chemically-produced organic acids [61].

Using HPLC analysis to detect some organic acid as citric acid and malic acid found that presence higher concentration of citric and malic in culturing of $2 \times 10^{6} \mathrm{SFU}$ of Aspergillus niger in $50 \mathrm{~mL}$ of modified ammonium medium and $0.5 \%$ e-waste than control flask without e-waste. These acids are used to leach copper from e-waste with decreasing $\mathrm{pH}$ of the solution from 7 to 4.2 .

It was observed that increased concentration of malic and citric acid in the sample in the presence of e-waste than the sample without e-waste as drawn in Figure 17, and this might be presence metals in e-waste act as coenzymes for enzymes used in the production of these organic acids in Krebs cycle in microorganism in addition to presence e-waste can make stress for Aspergillus niger that enhances and increase production of metabolites to thrive in these conditions. Wu and Ting [24] showed that the presence of manganese (a cofactor for the enzyme isocitrate dehydrogenase) so makes inhibition to accumulation of citric acid. This ewaste sample lacks manganese, so it activates to accumulate citric acid that is used in the dissolution process. Also, in the Krebs cycle, this enzyme catalyzes the oxidative decarboxylation of isocitrate to a-ketoglutarate, so, in a manganese-deficient medium, aketoglutarate is not produced, and the citric acid is accumulated in the culture medium. 
This result accepts $\mathrm{Wu}$ and Ting, [24], who reported that citric, oxalic, and gluconic acids produced by A. niger were enhancing factors that improve fungal bioleaching and metal extraction from municipal solid waste incinerator fly ash.
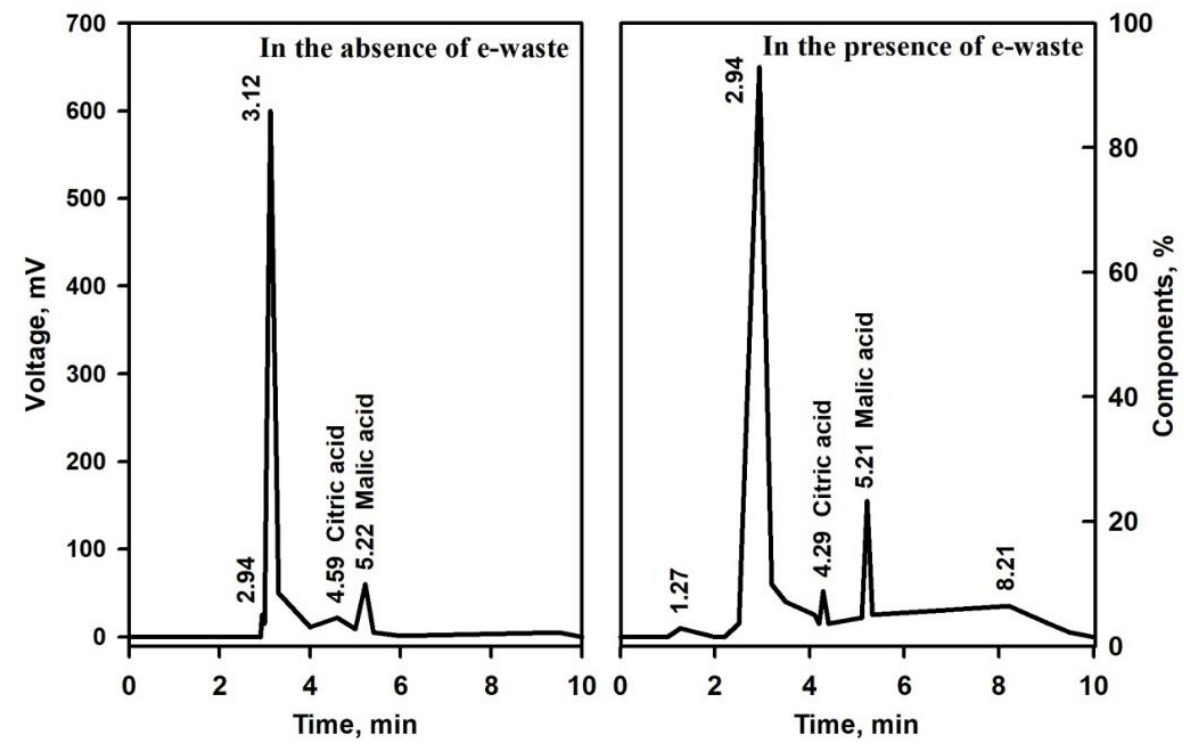

Figure 17. Detection of malic and citric acids using HPLC in the filtrate of A. niger culture in the absence and presence of the e-waste.

\subsection{SEM Analysis.}

SEM of e-waste before treatment was showed heterogeneity and variety of species of particles in the sample, as in Figure 18, A, and the smooth surface. SEM analysis of e-waste after treatment showed interaction of e-waste with A. niger as in Figure 17, (B,C) that resulted in increased the porosity of the surface and became rough due to large destruction of the structure by metabolites and organic acids were secreted by A. niger resulting in the dissolution of metals and came out to a solution. This agrees with Horeh et al. [22] showed that Aspergillus niger was used for bioleaching of metals from waste batteries made of lithium-ion based. Also, this result was confirmed by Lebbie et al., [62], who showed that the structural changes in the PCB after the bioleaching process had been identified by scanning electron microscope analysis.
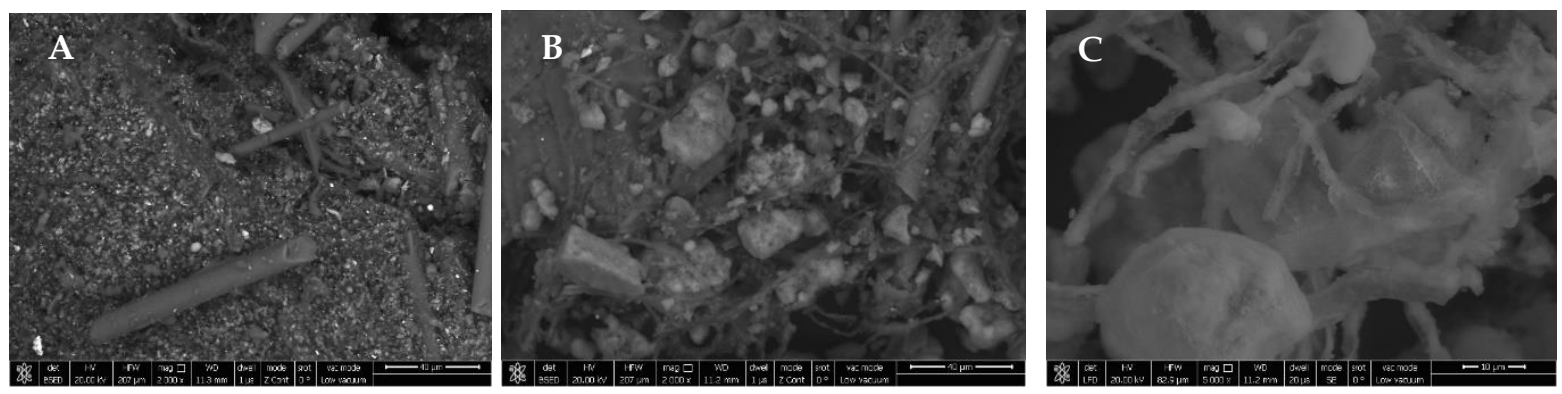

Figure 18. SEM images of e-waste before (A) and after the bioleaching process $(B, C)$.

\section{Conclusions}

This work was concerned with the extraction of copper from e-waste by using Aspergillus niger. These studies can be summarized as follows: Chemical analysis of e-waste was determined by XRF analysis and showed the high content of copper, reaching $21.96 \%$. Other elements such as $\mathrm{Br}, \mathrm{Sn}, \mathrm{Pb}, \mathrm{Zn}, \mathrm{Fe}$, and $\mathrm{Sb}$ were found; Aspergillus niger was isolated 
from Abu Tartur phosphate ore and identified by $18 \mathrm{~s}$ RNA. Tolerance of A. niger to copper was studied and found that optimum growth of $A$. niger up to $700 \mathrm{ppm}$ of copper concentration, then begun to decrease with increasing concentration of copper up to 1000ppm; Various bioleaching methods (one-step, two-step, spent medium) were tested and found that the twostep bioleaching method was the best method for extraction of copper; All parameters that affect copper dissolution efficiency were studied and revealed that maximum dissolution $(100 \%)$ can be achieved in the following conditions; modified ammonium medium with initial $\mathrm{pH} 7$ was the best bioleaching medium with inoculation $2 \times 10^{6} \mathrm{SFU}$ for $50 \mathrm{ml}$ at incubation period 5 days, incubation temperatures $30^{\circ} \mathrm{C}$ and shaking speed $200 \mathrm{rpm}$. Also, the best pulp density was $0.5 \%$ with a size fraction +150 mesh. Different carbon and nitrogen sources were tested, in addition to their concentrations, and found that $1.5 \%$ glucose was the best carbon source and $0.002 \mathrm{~g} / \mathrm{ml}$ ammonium chloride was the best nitrogen source; The mechanism of bioleaching was studied by detecting the produced organic acid through using brome cresol green as an indicator and found to change the color of the agar medium of the incubated plate from blue to yellow. Also, the bioleaching mechanism was studied by HPLC analysis through malic and citric acids detection in the sample without and with e-waste, which showed a malic and citric acid content in the sample with e-waste than the sample without e-waste; SEM investigation of the e-waste before and after the bioleaching process showed that the surface of e-waste after treatment becomes more smooth and porous than before treatment, referring to metals of e-waste dissolved during the process.

\section{Funding}

No funding.

\section{Acknowledgments}

This research has no acknowledgment.

\section{Conflicts of Interest}

The authors declare no conflict of interest.

\section{References}

1. Vinod, K.; Lee, J.C.; Jeong, J.; Kim, B.S. Review on mechanical recycling of end-life electronic equipments for recovery of metallic components. J. of the Korean Society for Geosystem Engineering 2010, 47, 5, 593608.

2. Maurice, A.; Din, K.; Charpentier, N.; Brambilla, A.; Gabriel, J-C. Dismantling of printed circuit boards enabling electronic components sorting and their subsequent treatment open improved elemental sustainability opportunities. Sustainability 2021, 13, 10357, https://doi.org/10.3390/su131810357.

3. Environment Victoria. Environment report card on computers, Computer Waste in Australia and The Case for Producer Responsibility. Environment Victoria 2005, Victoria.

4. Cui, J.; Forssberg, E. Mechanical recycling of waste electric and electronic equipment: a review, J. Hazard. Mater. 2003, 99, 243-263, https://doi.org/10.1016/S0304-3894(03)00061-X.

5. Sum, E.Y.L. The recovery of metals from electronic scrap. JOM 1991, 43, 53-61, https://doi.org/10.1007/BF03220549.

6. Koyama, K.; Tanaka, M.; Lee, J.C. Copper leaching behavior from waste printed circuit board in ammoniacal alkaline solution. Mater. Trans. 2006, 47, 1788-1792, https://doi.org/10.2320/matertrans.47.1788. 
7. International Copper Association. Copper: Its Trade, Manufacture, Use, and Environmental Status. Kundig, K.J.A., Gunter, J. (ed). ASM International 1999, 141-192.

8. Cui, J.; Zhang, L. Metallurgical recovery of metals from electronic waste: A review. J Hazard Mater 2008, 158, 228-256, https://doi.org/10.1016/j.jhazmat.2008.02.001.

9. Weidenhamer, J.D.; Clement, M.L. Leaded electronic waste is a possible source material for lead$\begin{array}{lllll}\text { contaminated } \quad \text { jewelry. } & \text { Chemosphere } & \text { 2007, } & \text { 69, }\end{array}$ https://doi.org/10.1016/j.chemosphere.2007.04.023.

10. Agate A.D. Recent advances in microbial mining. World Journal of Microbiology and Biotechnology 1996, 12, 487-495, https://doi.org/10.1007/BF00419462.

11. Bharadwaj, A., Ting, Y.P. From biomining of mineral ores to bio urban mining of industrial waste. Environ. Technol. Manag. Conf. 4th ETMC 2011, Bandung, Indonesia.

12. Johnson, D.B.; du Plessis, C.A. Biomining in reverse gear: Using bacteria to extract metals from oxidised ores. Minerals Engineering 2015, 75, 2-5, https://doi.org/10.1016/j.mineng.2014.09.024.

13. Alshehri, A.N.Z. Microbial Recovery of Gold Metal From Untreated and Pretreated Electronic Wastes by Wild and Mutated Cyanogenic Bacillus megaterium. American Journal of Microbiological Research 2018, 6, 14-21, http://dx.doi.org/10.12691/ajmr-6-1-3.

14. Rene, E.R.; Sethurajan, M.; Ponnusamy, V.K. ; Kumar, G.; Dung, T.N.B.; Brindhadevi, K.; Pugazhendhi, A. Electronic waste generation, recycling and resource recovery: Technological perspectives and trends. $J$ Hazard Mater 2021, 416, 125664, https://doi.org/10.1016/j.jhazmat.2021.125664.

15. Gadd, G.M., Bioremedial potential of microbial mechanisms of metal mobilization and immobilization. Curr Opin Biotechnol. 2000, 11, 271-279, https://doi.org/10.1016/S0958-1669(00)00095-1.

16. Elbarbary, T.A.; Hafez, M.A.; Ibrahim, I.A.; Abd EL-Halim, S.A.; Sharada, H.M.; Abdel-Fatah, Y.M. Bioleaching of Abu Tartur Phosphate Ore by Using Aspergillus niger. Haya: The Saudi J. of Life Sci. 2017, 2,10-22.

17. Sabouraud, R.Contribution al'etitude de la trichiphtie humaine. Etude clinique, microscopique et bacterioloqique sur la pluralite des trichophytons de l'homme. Ann. Dermatol. Syphilol. 1892, 3, 1061-1087.

18. Anwar, M.; Sumedha S.; Deshmukh; Killedar, N.; Narayan, L. Medium optimization, purification, characterization and specificity studies of extracellular RNase from Sreptomyces sp. (NCIM 2081) International Journal of Biological Chemistry. 2015, 9, 3, 133-141. https://doi.org/10.3923/ijbc.2015.133.141.

19. Thom, C.; Church, M. B. The Aspergilli. Williams and Wilkins Co. Baltimore 1926, 272.

20. Cunningham J.E.; Kuiack, C. Production of citric and oxalic acids and solublization of calcium phosphate by Penicillium bilaii. Appl. Environ. Microbiol. 1992, 52, 1451-1458, https://doi.org/10.1128/aem.58.5.14511458.1992.

21. Madrigal-Arias, J.E. et al. Bioleaching of gold, copper and nickel from waste cellular phone PCBs and computer goldfinger motherboards by two Aspergillus niger strains. Brazilian Journal of Microbiology 2015, 46, 707-713, https://doi.org/10.1590/s1517-838246320140256.

22. Horeh, N.B.; Mousavi, S.M.; Shojaosadati, S.A. Bioleaching of valuable metals from spent lithium-ion mobile phone batteries using Aspergillus niger. J. Power Sources 2016, 320, 257-266, https://doi.org/10.1016/j.jpowsour.2016.04.104.

23. Male, Y.; Seumahu, C.; Malle, D. Bioremediation of $\mathrm{Pb}$ and $\mathrm{Cd}$ Metal from Inner Ambon Bay Sediment Which Contaminated With Heavy Metal Using Aspergillus Niger. Indo. J. Chem. Res. 2020, 7, 183-188, https://doi.org/10.30598//ijcr.2020.7-yus.

24. Wu, H.-Y.; Ting, Y.-P. Metal extraction from municipal solid waste (MSW) incinerator fly ash - chemical leaching and fungal bioleaching. Enzyme Microb. Technol 2006, 38, 839-847, https://doi.org/10.1016/j.enzmictec.2005.08.012.

25. Iskandar, N.L.; Izzati, N.A.M.Z.; Tan, S.G. Tolerance and biosorption of copper $(\mathrm{Cu})$ and lead $(\mathrm{Pb})$ by filamentous fungi isolated from a freshwater ecosystem. Journal of Environmental Sciences 2011, 23, 824830, https://doi.org/10.1016/S1001-0742(10)60475-5.

26. Chauchan, R.; Tech, M.; Upadhyay, K. Removal of heavy metal from E-Waste: A review. IJCS 2015, 3, 1521. 
27. Dey, S.; Jana, T.E. E-Waste Recycling Technology Patents filed in India - An Analysis. Journal of Intellectual Property Rights 2014, 19, 315-324.

28. Grimm, L.; Kelly, S.; Hengstler, J.; Gobel, A.; Krull, R.; Hempel, D. Kinetic studies on the aggregation of Aspergillus niger conidia. Biotechnol Bioeng 2004, 87, 213-218, https://doi.org/10.1002/bit.20130.

29. Saravanan, P.; Pakshirajan, K.; Saha, P. Growth kinetics of an indigenous mixed microbial consortium during phenol degradation in a batch reactor. Bioresource Technology 2008, 99, 205-209, https://doi.org/10.1016/j.biortech.2006.11.045.

30. Ilyas, S.; Rajiv, R.S.; Kim, H.; Ilyas, N. Biotechnological recycling of hazardous waste PCBs using Sulfobacillus thermosulfidooxidans through pretreatment of toxicant metals: Process optimization and kinetic studies. Chemosphere 2022, 286, 131978, https://doi.org/10.1016/j.chemosphere.2021.131978.

31. Kolencik, M.; Urik, M.; Cernansky, S.; Molnarova, M.; Matus, P. Leaching of zinc, cadmium, lead and copper from electronic scrap using organic acids and the Aspergillus Niger strain. Fresenius Environmental Bulletin 2013, 22, 3673-3679.

32. Fagunwa, O.E.; Olanbiwoninu, A.A. Accelerating the sustainable development goals through microbiology: some efforts and opportunities. Access Microbiol. 2020, 2, acmi000174, https://doi.org/10.1099/acmi.0.000112.

33. Sevindik, M.; Dave, R.S; Sodha, A.B. Microbial technology for metal recovery from e-waste printed circuit $\begin{array}{llllll}\text { boards. Journal of Bacteriology and Mycology 2018, 6, 247, } & \text {, }\end{array}$ http://dx.doi.org/10.15406/jbmoa.2018.06.00212.

34. Mostafa, Y.S.; Alamri, S.A. Optimization of date syrup for enhancement of the production of citric acid using immobilized cells of Aspergillus niger. Saudi J Biol Sci. 2012, 19, 241-246, https://doi.org/10.1016/j.sjbs.2012.01.004.

35. Falguni, P.; Lakshmi, B. Bioleaching of copper and nickel from mobile phone printed circuit board using Aspergillus fumigatus A2DS. Brazilian Journal of Microbiology 2021, 52, 1475-1487, https://doi.org/10.1007/s42770-021-00526-y.

36. Castro, I.M.; Fietto, J.L.R.; Vieira, R.X.; Tropia, M.J.M.; Campos, L.M.M.; Paniago, E.B.; Brandao, R.L. Bioleaching of zinc and nickel from silicates using Aspergillus niger cultures. Hydrometallurgy 2000, 57, 3949, https://doi.org/10.1016/S0304-386X(00)00088-8.

37. Yaashikaa, P.R.; Priyanka, B.; Senthil Kumar, P.; Karishma, S.; Jeevanantham, S.; Sravya Indraganti. A review on recent advancements in recovery of valuable and toxic metals from e-waste using bioleaching approach. Chemosphere 2022, 287, 132230, https://doi.org/10.1016/j.chemosphere.2021.132230.

38. Liang, G.; Mo, Y.; Zhou, Q. Novel strategies of bioleaching metals from printed circuit boards (PCBs) in mixed cultivation of two acidophiles. Enzyme Microb. Technol. 2010, 47, 322-326, https://doi.org/10.1016/j.enzmictec.2010.08.002.

39. Wang, J.; Bai, J.; Xu, J.; Liang, B. Bioleaching of metals from printed wire boards by Acidithiobacillus ferrooxidans and Acidithiobacillus thiooxidans and their mixture. J. Hazard. Mater. 2009, 172, 1100-1105, https://doi.org/10.1016/j.jhazmat.2009.07.102.

40. Grewal, H.S; Kalra, K.L. Fungal production of citric acid. Biotechnol Adv. 1995, 13, 209-234, https://doi.org/10.1016/0734-9750(95)00002-8.

41. Ramadan, H.A.; El-Kadi, S.M.; Sand, M.I. Effect of some organic acids on some fungal growth and their toxins production. International Journal of Advances in Biology 2015, 2.

42. Patel, F.; Lakshmi, B. Bioleaching of copper and nickel from mobile phone printed circuit board using Aspergillus fumigatus A2DS. Brazilian Journal of Microbiology 2021, 52, 1475-1487, https://doi.org/10.1007/s42770-021-00526-y.

43. Wu, W.; Liu, X.; Zhang, X.; Zhu, M.; Ta, W. Bioleaching of copper from waste printed circuit boards by bacteria-free cultural supernatant of iron-sulfur-oxidizing bacteria. Bioresour. Bioprocess. 2018, 5, 10, https://doi.org/10.1186/s40643-018-0196-6.

44. Minimol, M.; Shetty, K.V.; Saidutta, M.B. Biohydrometallurgical methods and the processes involved in the bioleaching of WEEE. In book: Environmental Management of Waste Electrical and Electronic Equipment 2021, 89-107, http://dx.doi.org/10.1016/B978-0-12-822474-8.00005-2.

45. Gu, W.; Bai, J.; Dai, J.; Zhang, C.; Yuan, W.; Wang, J.; Wang, P.; Zhao, X. Characterization of Extreme Acidophile Bacteria (Acidithiobacillus ferrooxidans) Bioleaching Copper from Flexible PCB by ICP-AES. Journal of Spectroscopy 2014, 269351, https://doi.org/10.1155/2014/269351. 
46. Denaya, A.P.; Wilopo, W.; Warmada, I.W.; Retnanigrum, E. Optimization of manganese bioleaching activity and molecular characterization of indigenous heterotrophic bacteria isolated from the sulfuric area. Biodiversitas 2019, 20, 1904-1909, https://doi.org/10.13057/BIODIV\%2FD200716.

47. Papagianni, M.; Mattey, M. Morphological development of Aspergillus niger in submerged citric acid fermentation as a function of the spore inoculum level. Application of neural network and cluster analysis for characterization of mycelial morphology. Microbial Cell Factories 2006, 5, 3, https://doi.org/10.1186/14752859-5-3.

48. Saidan, M.; Brown, B.; Valix, M. Leaching of Electronic Waste Using Biometabolised Acids. Chinese Journal of Chemical Engineering 2012, 20, 530-534, https://doi.org/10.1016/S1004-9541(11)60215-2.

49. Erüst, C.; Akcil, A.; Gahan, C.S.; Tuncuk, A.; Deveci, H. Biohydrometallurgy of secondary metal resources: A potential alternative approach for metal recovery. J. Chem. Technol. Biotechnol. 2013, 88, 2115-2132, https://doi.org/10.1002/jctb.4164.

50. Rajarathinam, N.; Chandrasekaran, S.; Arunachalam, T. Electronic waste generation, regulation and metal recovery: a review. Environmental Chemistry Letters 2021, 19, 1347-1368.

51. Barosso, B.C.; Nahas, E. Enhanced solubilization of iron and calcium phosphates by Aspergillus niger by the addition of alcohols. Agriculture, Agribusiness and Biotechnology • Braz. arch. biol. technol. 2013, 56, https://doi.org/10.1590/S1516-89132013000200003.

52. Vandenberghe, L.P.S.; Soccol, C.R.; Pandey, A.; Lebeault, J-M. Microbial production of citric acid. Braz. arch. biol. technol. 1999, 42, https://doi.org/10.1590/S1516-89131999000300001.

53. Behera, B.C. Citric acid from Aspergillus niger: a comprehensive overview. Critical Reviews in Microbiology 2020, 46, 727-749, https://doi.org/10.1080/1040841x.2020.1828815.

54. Shetty, V.G. Production and optimization of citric acid by Aspergillus niger using molasses and corncob. International Journal of Pharmacy and Pharmaceutical Sciences 2015, 7 , https://innovareacademics.in/journals/index.php/ijpps/article/view/5327.

55. Hacıfazlıoğlu, H.; Kurşun, I.; Terzi, M. Performance of Organic and Inorganic Acids in the Extraction of Vanadium from Silica Sand by Leaching Method, Academic Platform - Journal of Engineering and Science 2020, 8, 478-482, https://doi.org/10.21541/apjes.530467.

56. Nyongesa, B.W.; Okoth, S.; Ayugi, V. Identification Key for Aspergillus Species Isolated from Maize and Soil of Nandi County, Kenya. Advances in Microbiology 2015, 5, http://dx.doi.org/10.4236/aim.2015.54020.

57. Tian, J.; Ge, F.; Zhang, D.; Deng, S.; Liu, X. Roles of Phosphate Solubilizing Microorganisms from managing soil phosphorus deficiency to mediating biogeochemical $\mathrm{P}$ cycle. Biology 2021, 10, 158, https://doi.org/10.3390/biology10020158.

58. Amato, A.; Becci, A.; Beolchini, F. Citric acid bioproduction: the technological innovation change. Critical Reviews in Biotechnology 2020, 40, 199-212, https://doi.org/10.1080/07388551.2019.1709799.

59. Shah, S.S.; Palmieri, M.C.; Sponchiado, S.R.P.; Bevilaqua, D. Enhanced bio-recovery of aluminum from low-grade bauxite using adapted fungal strains. Braz. J Microbiol. 2020, 51, 1909-1918.

60. Nikiema, M.; Somda, M.; Sawadogo, J.; Dianou, D.; Traoré, A.; Ouattara, A. Valorization of Agricultural Waste: Theoretical Estimation and Experimental Biomethane Yield from Cashew Nut Hulls. Journal of Sustainable Bioenergy Systems 2020, 10, 113-130, https://doi.org/10.4236/jsbs.2020.104009.

61. Li, Z.; Bai, T.; Dai, L.; Wang, F.; Tao, J.; Meng, S.; Hu, Y.; Wang, S.; Hu, S. A study of organic acid production in contrasts between two phosphate solubilizing fungi: Penicillium oxalicum and Aspergillus niger. Sci Rep. 2016, 6, 25313, https://doi.org/10.1038/srep25313.

62. Lebbie, T.S.; Moyebi, O.D.; Asante, K.A.; Fobil, J.; Brune-Drisse, M.N.; Suk, W.A.; Sly, P.D.; Gorman, J.; Carpenter, D.O. E-Waste in Africa: A Serious Threat to the Health of Children. Int J Environ Res Public Health 2021, 18, 8488, https://doi.org/10.3390/ijerph18168488. 